\title{
Modeling of \\ Atomic Clock Performance and Detection of Abnormal Clock Behavior
}

U.S. IEPARTMENT OF COMMERCE National Rıreau QC If 100 is U5753 no. 636 1973 C.2 
The National Bureau of Standards ${ }^{1}$ was established by an act of Congress March 3 , 1901. The Bureau's overall goal is to strengthen and advance the Nation's science and technology and facilitate their effective application for public benefit. To this end, the Bureau conducts research and provides: (1) a basis for the Nation's physical measurement system, (2) scientific and technological services for industry and government, (3) a technical basis for equity in trade, and (4) technical services to promote public safety. The Bureau consists of the Institute for Basic Standards, the Institute for Materials Research, the Institute for Applied Technology, the Center for Computer Sciences and Technology, and the Office for Information Programs.

THE INSTITUTE FOR BASIC STANDARDS provides the central basis within the United States of a complete and consistent system of physical measurement; coordinates that system with measurement systems of other nations; and furnishes essential services leading to accurate and uniform physical measurements throughout the Nation's scientific community, industry, and commerce. The Institute consists of a Center for Radiation Research, an Office of Measurement Services and the following divisions:

Applied Mathematics — Electricity - Mechanics - Heat - Optical Physics Linac Radiation ${ }^{2}$ - Nuclear Radiation ${ }^{2}$ - Applied Radiation ${ }^{2}$ — Quantum Electronics * Electromagnetics * - Time and Frequency ${ }^{3}$ — Laboratory Astrophysics:: Cryogenics ${ }^{3}$.

THE INSTITUTE FOR MATERIALS RESEARCH conducts materials research leading to improved methods of measurement, standards, and data on the properties of well-characterized materials needed by industry, commerce, educational institutions, and Government; provides advisory and research services to other Government agencies; and develops, produces, and distributes standard reference materials. The Institute consists of the Office of Standard Reference Materials and the following divisions:

Analytical Chemistry-Polymers-Metallurgy-Inorganic Materials-Reactor Radiation-Physical Chemistry.

THE INSTITUTE FOR APPLIED TECHNOLOGY provides technical services to promote the use of available technology and to facilitate technological innovation in industry and Government; cooperates with public and private organizations leading to the development of technological standards (including mandatory safety standards), codes and methods of test; and provides technical advice and services to Government agencies upon request. The Institute also monitors NBS engineering standards activities and provides liaison between NBS and national and international engineering standards bodies. The Institute consists of a Center for Building Technology and the following divisions and offices:

Engineering and Product Standards-Weights and Measures-Invention and Innovation-Product Evaluation Technology-Electronic Technology-Technical Analysis-Measurement Engineering-Building Standards and Code Services $^{4}$ - Housing Technology ${ }^{4}$ - Federal Building Technology ${ }^{4}$ - Structures, Materials and Life Safety ${ }^{4}$-Building Environment ${ }^{4}-$ Technical Evaluation and Application ${ }^{4}$-Fire Technology.

THE INSTITUTE FOR COMPUTER SCIENCES AND TECHNOLOGY conducts research and provides technical services designed to aid Government agencies in improving cost effectiveness in the conduct of their programs through the selection, acquisition, and effective utilization of automatic data processing equipment; and serves as the principal focus within the executive branch for the development of Federal standards for automatic data processing equipment, techniques, and computer languages. The Center consists of the following offices and divisions:

Information Processing Standards-Computer Information-Computer Services - Systems Development-Information Processing Technology.

THE OFFICE FOR INFORMATION PROGRAMS promotes optimum dissemination and accessibility of scientific information generated within NBS and other agencies of the Federal Government; promotes the development of the National Standard Reference Data System and a system of information analysis centers dealing with the broader aspects of the National Measurement System; provides appropriate services to ensure that the NBS staff has optimum accessibility to the scientific information of the world, and directs the public information activities of the Bureau. The Office consists of the following organizational units:

Office of Standard Reference Data-Office of Technical Information and Publications-Library-Office of International Relations.

\footnotetext{
1 Headquarters and Lahoratories at Gaithersburg, Maryland, unless otherwise noted; malling address ${ }^{1}$ Headquarters and Lahorat
Washington, D.C. 20234 .

2 Part of the Center for Radiation Research.

3 Loeated at Boulder, Colorado 80302

4 Part of the Center for Building T'echnology.
} 


\section{Modeling of Atomic Clock Performance and Detection of Abnormal Clock Behavior}

\section{William A. Gahter}

Department of Engineering Design and Economic Evaluation

Lniversity of Colorado

Final Report on Research Sponsored by Time and Frequency Division Institute for Basic Standards

U.A. National Bureau of Standards

Boulder, Colorado 80302

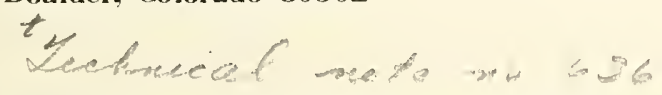

NBS Technical notes are designed to supplement the Bureau's regular publications program. They provide a means for making available scientific data that are of transient or limited interest. Technical Notes may be listed or referred to in the open literature.

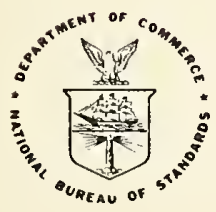

U.S. DEPARTMENT OF COMMERCE, Frederick B. Dent, Secretary NATIONAL BUREAU OF STANDARDS, Richard W. Roberts, Director Issued March 1973 


\section{National Bureau of Standards Technical Note 636}

Nat. Bur. Stand. (C.S.). Tech. Note 636, 39 pages (March 1973)

CODEN: NBTNAE

For sale by the Superintendent of Documents, U.S. Government Printing Office, Washington, D. C. 20402 (1)riler lo sl) (atalog No. (i13.16:6336) 
Contents

1. Introduction ................... . . . Page

2. Noise Model. . . . . . . . . . . . . . . 4

3. Structure of the Detection Procedures . . . . . . . . 9

4. Experimental Development and Evaluation . . . . . . 13

4.1. Development of the Detection Procedures . . . . . 13

4.2. Evaluation of the Detection Procedures . . . . . . 14

5. Conclusions . . . . . . . . . . . . . 29

6. References . . . . . . . . . . . . 30 


\section{List of Figures}

Figure

Page

1 A nominal run with $(\mathrm{a}, \mathrm{b})=(.7, .3)$ and no

detection in 512 days.

A nominal run with $(a, b)=(.7, .3)$ and no

detection in 512 days.

3 A nominal run with $(a, b)=(.8, .2)$ and no detection in 512 days.

4 A nominal run with $(\mathrm{a}, \mathrm{b})=(.8, .2)$ and no detection in 512 days.

5 A nominal run with $(\mathrm{a}, \mathrm{b})=(.8, .2)$ and no detection in 512 days.

Detection of a $J=-3.4$ jump by eq (23) when $(\mathrm{a}, \mathrm{b})=(.8, .2)$ and $\mathrm{t}_{\mathrm{c}}=35$.

7 Detection of a $J=-3.2$ jump by eq (23) when $(\mathrm{a}, \mathrm{b})=(.8, .2)$ and $\mathrm{t}_{\mathrm{c}}=34$.

8 Detection of a $J=3.5$ jump by eq (23) when $(\mathrm{a}, \mathrm{b})=(.7, .3)$ and $\mathrm{t}_{\mathrm{c}}=25$.

9 Detection of a $J=3.0$ jump by eqs (24), (25), and (26) when $(a, b)-(.7, .3)$ and $t_{c}=35$.

10 Detection of a $D=1.0$ time drift by eq (31) when $(\mathrm{a}, \mathrm{b})=(.8, .2)$ and $\mathrm{t}_{\mathrm{c}}=35$.

11 Detection of a $D=1.5$ time drift by eq (31) when $(\mathrm{a}, \mathrm{b})-(.7, .3)$ and $\mathrm{t}_{\mathrm{c}}=31$.

12 Detection of a $\mathrm{D}=-.1, \mathrm{Q}=-.02$ time and rate drift by eq (32) when $(a, b)-(.7, .3)$ and $t_{c}=28$.

13 Detection of a $D=.2, Q=.05$ time and rate drift by eq (31) when $(a, b)=(.7, .3)$ and $t_{c}=320$.

14 Detection at day 126 of noise change $\beta=.6$ when $(\mathrm{a}, \mathrm{b})=(.7, .3)$ and $\mathrm{t}_{\mathrm{c}}=28$.

15 Detection at day 301 of noise change $\beta=.1$ when $(\mathrm{a}, \mathrm{b})=(.7, .3)$ and $\mathrm{t}_{\mathrm{c}}=26$.

16 Detection at day 271 of noise change $\beta=.5$ when $(\mathrm{a}, \mathrm{b})=(.7, .3)$ and $\mathrm{t}_{\mathrm{c}}=28$. 
List of Figures (cont'd.)

Figure

Page

17 Detection at day 111 of noise change $\alpha=.9$ when 25 $(\mathrm{a}, \mathrm{b})=(.7, .3)$ and $\mathrm{t}_{\mathrm{c}}=24$.

18 Detection at day 216 of noise change $\alpha=.5$ when 26 $(\mathrm{a}, \mathrm{b})=(.7, .3)$ and $\mathrm{t}_{\mathrm{c}}=28$.

19 False inference at day 111 that $\alpha>.7$ when actually $\beta=.5 . \quad(a, b)=(.7, .3)$ and $t_{c}=26$.

$20 \quad$ False inference at day 81 that $\alpha>.7$ when actually $\beta=.1 .(\mathrm{a}, \mathrm{b})=(.7, .3)$ and $\mathrm{t}_{\mathrm{c}}=31$.

21 False detection of a jump by eq (23) at day 164 when actually $\beta=.5 . \quad(a, b)=(.7, .3)$ and $t_{c}=26$.

22 False detection of a drift by eq (31) at day 316 when actually $\beta=.4 . \quad(a, b)=(.7, .3)$ and $t_{c}=28$.

23 False detection of a drift by eq (31) at day 276 when actually $\beta=.4 . \quad(a, b)=(.8, .2)$ and $t_{c}=29$.

\section{List of Tables}

Table 



\section{William A. Ganter}

We have assumed that the nominal performance of an atomic clock can be well characterized by (1) a noise amplitude and (2) a mix of white and flicker pure noise processes. A number of specific kinds of changes are assumed that a clock might encounter. We assume that these changes can occur with either sign and with varying magnitudes. The changes considered are a noise amplitude different from nominal, a flicker component in the noise mix which is different from nominal, a step jump in the time counts for a clock and a linear (frequency jump) or quadratic (frequency drift) trend in the time counts for a clock.

Detection of a change is accomplished with a multiple sequential test having compound limits. The test is designed to respond quickly to an actual change but to make few incorrect detections (identify the wrong change) or false detections (when no change from nominal operation has occurred!. When a change is detected for a clock, the laboratory time scale can be adjusted accordingly for this condition. Key words: Atomic clock model; detection; flicker noise; sequential test; time scale.

\section{Introduction}

A recent paper by Allan, Gray, and Machlan [1] gives a comprehensive view of the AT(NBS) time scale. These authors discuss the influence of an individual commercial cesium beam clock on this time scale. Of special interest for this report is a section of [1] on clock modeling where the belief is expressed that a clock can experience 
changes in its rate due to either internal or external perturbations. In addition, the interpretation of "time" from a clock is subject to counting noise. A prominent model of clock noise is a mix of two kinds of noise: white FM and flicker FM noise processes. These noise processes are discussed in [2], [3], and [4].

In [1] the authors disclose that a weight $w_{i}$ is used to incorporate measured counts from clock $i$ into the AT(NBS) scale. They state that this weight depends upon the quality of performance that clock i is expected to give. This means that the intensity and the kinds of noise processes affect the weighting. The assumption of the quality of performance for clock i must be derived from a comparison of clock i with other clocks or from its direct calibration with a primary standard.

Under the assumption that the noise process of a clock might change or that its rate might change, this research addresses the problem of detecting changes in the performance of a clock. The noise changes considered are intensity (amplitude) changes in either the white FM or flicker FM component. The other changes are a jump in time, a drift in time, or a drift in rate. The objective is to explore detection schemes which have the following properties:

1. Make few false detections;

2. Ignore very minute changes;

3. Respond rapidly to large changes; and

4. Identify the type of change correctly.

Unfortunately these desired characteristics are in conflict in a number of ways. Very rapid detection of a change causes more false detections. Trying to detect very small changes causes more false detections. Trying to distinguish between many changes causes more detections for the wrong reason. Therefore, a good detection scheme is one which maintains a suitable balance between the goals of the detection procedure. It is also one which responds quickly to actual 
changes but makes only an acceptable number of false detections. A design goal for the procedures developed in this project was to make a false detection on the average only once per year with daily testing for changes.

Detection schemes are used in many other applications. Two very prominent examples are quality control and submarine warfare. Other examples are early failure detection for operating machinery and aircraft engines, medical diagnosis, and environmental control. Graphs comparing the false detection frequency and the speed of detection of various magnitudes of changes are often called operating characteristic curves. Another related notion is that machines are conceived to operate in a particular manner by their designers. Often a failure of some type occurs causing abnormal performance from the machine. A detection scheme can be devised to recognize non-nominal behavior when it is important to be aware of such conditions.

The statistical techniques used in this research are moving averages, geometric smoothing, estimation, prediction, likelihood functions, and comparisons of quantities against limits. The procedures (which are really hypothesis tests) are multiple sequential tests using compound limits to better distinguish between possible changes. Geometric smoothing is often employed to require a persistence of evidence before a detection is made.

In section 2, we discuss the noise model of a clock that we have used in this study. Section 3 shows the structure of the multiple detection schemes which resulted from the experimental development using simulation of a clock. The bulk of the effort in this study was devoted to the development of a multiple test which was consistent with the design goals. Section 4 discusses this experimental development and then discusses the results of an experimental evaluation of the procedures of section 3. Section 5 gives conclusions and recommendations for 
additional study. No attempt was made to specify any adjustments to be made to a time scale after a change was detected. A change might suggest a revision of the $w_{i}$ weights or a one time increment to be applied to the scale.

\section{Noise Model}

The noise process about the rate of an atomic clock considered in this study has a white noise FM component and a flicker noise FM component. The white FM process has constant spectral density of the frequency fluctuation while the flicker process has a spectral density of the frequency fluctuation inversely proportional to the Fourier frequency. Let us consider other properties of these stochastic processes, the autocovariance function and the Allan variance. The Allan variance is specified as a sample statistic (time averaging of a process realization) in [2], [3], and [4]. It will be convenient to view this measure of frequency stability in its expectation form in this section.

Let $W_{t}$ for $t=0,1, \ldots, \infty$ be a white noise stochastic process. Let $t$ be a day index; however, other counting intervals a re equally valid. Let us also denote a realization of the $W_{t}$ process by $w_{t}$. We also assume that random variable $W_{t}$ is normally distributed with mean 0 and unit variance. The process outcomes at various days are independent, thus the autocovariance function

and

$$
A_{W}(\tau)=\operatorname{Cov}\left(W_{t}, W_{t+\tau}\right)=0, \text { for } \tau>0 \text {, }
$$

$$
A_{W}(0)=\operatorname{Var}\left(W_{t}\right)=1
$$

Let $\sigma_{W}^{2}(\tau)$ denote the Allan variance for the ${ }^{\prime} W_{t}$ noise process. We define

$$
\sigma_{W}^{2}(1)=\frac{E\left[\left(W_{t}-W_{t+1}\right)^{2}\right]}{2}
$$


This expectation expands to

$$
\begin{aligned}
& \frac{E\left[W_{t}^{2}\right]-2 E\left[W_{t} W_{t+1}\right]+E\left[W_{t+1}^{2}\right]}{2} \\
& =\frac{E\left[W_{t}^{2}\right]-2 E\left[W_{t}\right] E\left[W_{t+1}\right]+E\left[W_{t+1}^{2}\right]}{2} \\
& =\frac{E\left[W_{t}^{2}\right]+E\left[W_{t+1}^{2}\right]}{2},
\end{aligned}
$$

since $W_{t}$ and $W_{t+1}$ are independent random variables. By definition we have that $\mathrm{W}_{t+1}{ }^{2}$ is distributed chi-square with 1 degree of freedom; the expected value of a chi-square random variable with 1 degree of freedom is 1 . Thus,

$$
\sigma_{W}^{3}(1)=\frac{1+1}{2}=1
$$

Next consider

$$
\begin{aligned}
\sigma_{W}^{2}(2) & =\frac{E\left[\left(\frac{W_{t}+W_{t+1}}{2}-\frac{W_{t+2}+W_{t+3}}{2}\right)^{2}\right]}{2} \\
& =\frac{1+1}{4}-\frac{2(0)}{4}+\frac{1+1}{4}=\frac{1}{2} .
\end{aligned}
$$

In similar fashion it is ea sily shown that

$$
\sigma_{\mathrm{W}}^{2}(\tau)=\frac{1}{\tau} \text {. }
$$

Let $F_{t}$ be a flicker noise stochastic process. It is shown in [4] that

$$
\sigma_{F}^{2}(\tau)=c \text {, a constant. }
$$

However, the autocovariance function

$$
A_{F}(\tau) \neq 0 \text { for any } \tau \text {. }
$$

The flicker process is thought to be positively autocorrelated for all $\tau$; this result should be demonstrable using eq (4) and the definition of $\mathrm{A}_{\mathrm{F}}(\tau)$ since many similar terms are present. It is necessary to divide 
$F_{t}$ by $c$ so that

$$
\sigma_{F}^{3}(\tau)=1
$$

in this model.

Let us define noise stochastic process

$$
Z_{t}=a W_{t}+b F_{t} \text {, }
$$

where $a+b=1$. The Allan variance for this process is

$$
\sigma_{Z}^{3}(\tau)=\frac{a^{3}}{\tau}+b^{2} \text {. }
$$

For $\tau=1$ in eq (8) we see that

$$
\begin{aligned}
\sigma_{Z}^{3}(1) & =\frac{E\left[\left(a W_{t}-a W_{t+1}\right)^{3}\right]}{2}+\frac{E\left[\left(b F_{t}-b F_{t+1}\right)^{3}\right]}{2} \\
& =a^{2} \sigma_{W}^{2}(1)+b^{3} \sigma_{F}^{3}(1) .
\end{aligned}
$$

Henceforth, let us denote the Allan variance of the $Z_{t}$ process by simply $\sigma^{2}(\tau)$. We will let $\hat{\sigma}^{2}(\tau)$ be an estimate of the Allan variance from a particular process realization. Let us also define the notation

$$
\operatorname{sigma}(a, b, \tau)=\sqrt{\frac{a^{3}}{\tau}+b^{2}} \text {. }
$$

Table 1 gives values of this function for a and $b$ equal to $0 ., .1, .2, \ldots$, 1. and $\tau+1,2,4$ and 8 .

Let us also define a particular estimate of the Allan variance for the $Z_{t}$ process with outcomes $z_{t}$ by

$$
\hat{\sigma}_{T}^{2}(\tau)=\frac{\sum_{i=1}^{\frac{T}{\tau}-1}\left(\bar{z}_{i}-\bar{z}_{i+1}\right)^{2}}{2\left(\frac{T}{\tau}-1\right)},
$$

where $\bar{z}_{i}$ is the arithmetic average of the $i-t h$ group of $\tau Z_{t}$ outcomes. For comparison, a common estimator for the autocovariance function is 


$$
\hat{A}_{T}(\tau)=\frac{1}{T-\tau} \sum_{t=1}^{T-\tau}\left(z_{t}-\bar{z}\right)\left(z_{t+\tau}-\bar{z}\right),
$$

for $\tau=0,1, \ldots, \mathrm{T}-1$ and where $\bar{z}$ is the average over all $\mathrm{T}$ outcomes of $Z_{t}$.

TABLE 1. FUNCTION SIGMA $(a, b, \tau)$.

$$
\operatorname{sigma}(a, b, 1)
$$

$\mathrm{b}$

$\begin{array}{lllllllllll}0 . & .1 & .2 & .3 & .4 & .5 & .6 & .7 & .8 & .9 & 1.0\end{array}$

\begin{tabular}{|c|c|c|c|c|c|c|c|c|c|c|c|}
0. & 0.000 & .100 & .200 & .300 & .400 & .500 & .600 & .700 & .800 & .900 & 1.000 \\
.1 & .100 & .141 & .224 & .316 & .412 & .510 & .608 & .707 & .806 & .906 & 1.005 \\
.2 & .200 & .224 & .283 & .361 & .447 & .539 & .632 & .728 & .825 & .922 & 1.020 \\
.3 & .300 & .316 & .361 & .424 & .500 & .583 & .671 & .762 & .854 & .949 & 1.044 \\
.4 & .400 & .412 & .447 & .500 & .566 & .640 & .721 & .806 & .894 & .985 & 1.077 \\
\hline .5 & .500 & .510 & .539 & .583 & .640 & .707 & .781 & .860 & .943 & 1.030 & 1.118 \\
.6 & .600 & .608 & .632 & .671 & .721 & .781 & .849 & .922 & 1.000 & 1.082 & 1.166 \\
.7 & .700 & .707 & .728 & .762 & .806 & .860 & .922 & .990 & 1.063 & 1.140 & 1.221 \\
.8 & .800 & .806 & .825 & .854 & .894 & .943 & 1.000 & 1.063 & 1.131 & 1.204 & 1.281 \\
.9 & .900 & .906 & .922 & .949 & .985 & 1.030 & 1.082 & 1.140 & 1.204 & 1.273 & 1.345 \\
1.0 & 1.000 & 1.005 & 1.020 & 1.044 & 1.077 & 1.118 & 1.166 & 1.221 & 1.281 & 1.345 & 1.414 \\
\hline
\end{tabular}

$\operatorname{sigma}(a, b, 2)$

b

$\begin{array}{lllllllllll}0 . & .1 & .2 & .3 & .4 & .5 & .6 & .7 & .8 & .9 & 1.0\end{array}$

\begin{tabular}{|c|c|c|c|c|c|c|c|c|c|c|c|}
0. & 0.000 & .100 & .200 & .300 & .400 & .500 & .600 & .700 & .800 & .900 & 1.000 \\
.1 & .071 & .122 & .212 & .308 & .406 & .505 & .604 & .704 & .803 & .903 & 1.002 \\
.2 & .141 & .173 & .245 & .332 & .424 & .520 & .616 & .714 & .812 & .911 & 1.010 \\
.3 & .212 & .235 & .292 & .367 & .453 & .543 & .636 & .731 & .828 & .925 & 1.022 \\
0.4 & .283 & .300 & .346 & .412 & .490 & .574 & .663 & .755 & .849 & .943 & 1.039 \\
.5 & .354 & .367 & .406 & .464 & .534 & .612 & .696 & .784 & .875 & .967 & 1.061 \\
.6 & .424 & .436 & .469 & .520 & .583 & .656 & .735 & .819 & .906 & .995 & 1.086 \\
.7 & .495 & .505 & .534 & .579 & .636 & .704 & .778 & .857 & .941 & 1.027 & 1.116 \\
.8 & .566 & .574 & .600 & .640 & .693 & .755 & .825 & .900 & .980 & 1.063 & 1.149 \\
1.9 & .636 & .644 & .667 & .704 & .752 & .809 & .875 & .946 & 1.022 & 1.102 & 1.185 \\
\hline .707 & .714 & .735 & .768 & .812 & .866 & .927 & .995 & 1.068 & 1.145 & 1.225 \\
\hline
\end{tabular}


Table 1. (continued)

$\operatorname{sigma}(a, b, 4)$

b

\begin{tabular}{|c|c|c|c|c|c|c|c|c|c|c|c|}
\hline & 0 . & .1 & .2 & .3 & .4 & .5 & .6 & .7 & .8 & .9 & 1.0 \\
\hline 0. & 0.000 & .100 & .200 & .300 & .400 & .500 & .600 & .700 & .800 & .900 & 1.000 \\
\hline .1 & .050 & .112 & .206 & .304 & .403 & .502 & .602 & .702 & .802 & .901 & 1.001 \\
\hline 2 & .100 & .141 & .224 & .316 & .412 & .510 & .608 & .707 & .806 & .906 & 1.005 \\
\hline .3 & .150 & .180 & .250 & .335 & .427 & .522 & .618 & .716 & .814 & .912 & 1.011 \\
\hline .4 & .200 & .224 & .283 & .361 & .447 & .539 & .632 & .728 & .825 & .922 & 1.020 \\
\hline .5 & .250 & .269 & .320 & .391 & .472 & .559 & .650 & .743 & .838 & .934 & 1.031 \\
\hline .6 & . 300 & .316 & .361 & .424 & .500 & .583 & .671 & .762 & .854 & . 949 & 1.044 \\
\hline .7 & .350 & .364 & .403 & .461 & .532 & .610 & .695 & .783 & .873 & .966 & 1.059 \\
\hline .8 & .400 & .412 & .447 & .500 & .566 & .640 & .721 & .806 & .894 & .985 & 1.077 \\
\hline .9 & .450 & .461 & .492 & .541 & .602 & .673 & .750 & .832 & .918 & 1.006 & 1.097 \\
\hline 1.0 & .500 & .510 & .539 & .583 & .640 & .707 & .781 & .860 & . 943 & 1.030 & 1.118 \\
\hline
\end{tabular}

$\operatorname{sigma}(a, b, 8)$

$\mathrm{b}$

$\begin{array}{lllllllllll}0 . & .1 & .2 & .3 & .4 & .5 & .6 & .7 & .8 & .9 & 1.0\end{array}$

\begin{tabular}{|c|c|c|c|c|c|c|c|c|c|c|c|}
0. & 0.000 & .100 & .200 & .300 & .400 & .500 & .600 & .700 & .800 & .900 & 1.000 \\
.1 & .035 & .106 & .203 & .302 & .402 & .501 & .601 & .701 & .801 & .901 & 1.001 \\
.2 & .071 & .122 & .212 & .308 & .406 & .505 & .604 & .704 & .803 & .903 & 1.002 \\
.3 & .106 & .146 & .226 & .318 & .414 & .511 & .609 & .708 & .807 & .906 & 1.006 \\
.4 & .141 & .173 & .245 & .332 & .424 & .520 & .616 & .714 & .812 & .911 & 1.010 \\
\hline .5 & .177 & .203 & .267 & .348 & .437 & .530 & .625 & .722 & .819 & .917 & 1.016 \\
.6 & .212 & .235 & .292 & .367 & .453 & .543 & .636 & .731 & .828 & .925 & 1.022 \\
.7 & .247 & .267 & .318 & .389 & .470 & .558 & .649 & .742 & .837 & .933 & 1.030 \\
.8 & .283 & .300 & .346 & .412 & .490 & .574 & .663 & .755 & .849 & .943 & 1.039 \\
.9 & .318 & .334 & .376 & .437 & .511 & .593 & .679 & .769 & .861 & .955 & 1.049 \\
1.0 & .354 & .367 & .406 & .464 & .534 & .612 & .696 & .784 & .875 & .967 & 1.061 \\
\hline
\end{tabular}




\section{Structure of the Detection Procedures}

In this section we merely present the detection procedures developed in this research. The rationale behind them is defended in the next section. Let $\mathrm{T}_{t}$ denote the time from a clock at day $t$; we update time by

$$
T_{t}=T_{t-1}+z_{t}
$$

Let us first consider the tests for a noise intensity change from eq (7) of either of two types:

$$
Z_{t}=a W_{t}+B F_{t}
$$

or

$$
\mathrm{Z}_{\mathrm{t}}=\alpha \mathrm{W}_{\mathrm{t}}+\mathrm{b} \mathrm{F}_{\mathrm{t}} \text {, }
$$

where $\alpha$ and $\beta$ are changed values of a and $b$, respectively.

An estimate of $\sigma(\tau)$ is obtained by letting $T=16$ in eq (10). Every 5 days thereafter let our estimate of $\hat{\sigma}(\tau)$ be replaced by

$$
.95 \hat{\sigma}(\tau)+.05 \hat{\sigma}(\tau) \text {. }
$$

At day 16 we start the estimator with $\hat{\sigma}(\tau)=\hat{\sigma}_{16}(\tau)$. The noise test is performed every 5 days.

It proved necessary to adjust the $\hat{\sigma}_{16}(\tau)$ values to make them more closely correspond to the theoretical values of the sigma (a, b, $\tau$ ) function. The multiplicative factors at $\tau=1,2,4,8$ a re $.97,1.02,1.05,1.11$, respectively. The need for this correction stems from a minor imperfection in the flicker generator [5] and from a skewed sampling distribution for $\hat{\sigma}_{16}(\tau)$. The sampling skew is suggested by a nalogy to the following example. Let random variable $X$ be distributed chi-square with 1 degree of freedom. The $E[X]=1$ and the $\operatorname{Pr}\{X<1\}$ is approximately equal to .7 . So we infer by analogy that in a small sample of $X$ outcomes, a number of low values is very probable. Since $\hat{\sigma}_{16}(8)$ is estimated from a single sample it often assumes a value lower than sigma $(a, b, 8)$. Different correction factors would likely be better for $\mathrm{T} \neq 16$. 
A likelihood test is used to detect a noise change. Assume that $\hat{\sigma}(1)$ has a greater value than nominal in a realization. This suggests that a noise intensity increase may have occurred such that either $\alpha>\mathrm{a}$ or $\beta>\mathrm{b}$; we need to determine which one or neither (the test does not explicitly look for a change in both).

$$
\text { If } \hat{\sigma}(1)>\min \{\operatorname{sigma}(a+.1, b, 1) ; \operatorname{sigma}(a, b+.1,1)\} \text {, }
$$

a threshold value, let us start the following procedure. The first day that $\hat{\sigma}(1)$ exceeds the threshold value let $x_{1}=x_{2}=0$ and $x_{3}=1$. At other times we update the $x_{i}$ values. We interpolate twice on $\hat{\sigma}(1)$ to obtain the best fit to both sigma $(a, b ; 1)$ and sigma $\left(a{ }^{\prime}, b, 1\right)$. Then we compute the absolute differences

$$
\begin{aligned}
& \mathrm{d}_{1}=\sum_{\tau=1,2,4,8}\left|\hat{\sigma}(\tau)-\operatorname{sigma}\left(\mathrm{a}, \mathrm{b}^{\prime}, \tau\right)\right| \\
& \mathrm{d}_{2}=\sum_{\tau=1,2,4,8}|\hat{\sigma}(\tau)-\operatorname{sigma}(\mathrm{a}, \mathrm{b}, \tau)| \\
& \mathrm{d}_{3}=\sum_{\tau=1,2,4,8}|\hat{\sigma}(\tau)-\operatorname{sigma}(\mathrm{a}, \mathrm{b}, \tau)| .
\end{aligned}
$$

We update the $x_{i}$ by replacement signified as

$$
x_{i}=.75 x_{i}+.25\left(\frac{\frac{l}{d_{i}}}{\frac{l}{d_{1}}+\frac{l}{d_{2}}+\frac{l}{d_{3}}}\right) .
$$

In similar manner, if

$$
\hat{\sigma}(1)<\max \{\operatorname{sigma}(a-.1, b, 1) ; \operatorname{sigma}(a, b-.1,1)\}
$$

we start $y_{1}=y_{2}=0$ and $y_{3}=1$ the first time the threshold is exceeded and update on subsequent consecutive times. We interpolate on $\hat{\sigma}(1)$ again for both possible changes and compute $d_{i}$ as above and update the $\mathrm{y}_{\mathrm{i}}$ by replacement signified as

$$
y_{i}=.75 y_{i}+.25\left(\frac{\frac{1}{d_{i}}}{\frac{1}{d_{1}}+\frac{1}{d_{2}}+\frac{1}{d_{3}}}\right) .
$$


Thus, the $\sum_{i=1}^{3} x_{i}=\sum_{i=1}^{3} y_{i}=1$ always.

The test using compound limits is

$$
\begin{aligned}
& \text { when } \mathrm{x}_{1}>.55 \text { and } \mathrm{x}_{3}<.20 \text { detect } \beta>\mathrm{b} \\
& \text { when } \mathrm{y}_{1}>.55 \text { and } \mathrm{y}_{3}<.20 \text { detect } \alpha>\mathrm{a} \\
& \text { when } \mathrm{x}_{2}>.55 \text { and } \mathrm{x}_{3}<.20 \text { detect } \beta<\mathrm{b} \\
& \text { when } \mathrm{y}_{2}>.55 \text { and } \mathrm{y}_{3}<.20 \text { detect } \alpha<\mathrm{a} .
\end{aligned}
$$

This test has 7 parameters. For review they are

1. $T=16$ day averaging interval;

2. Smooth every 5 days into $\hat{\sigma}(\tau)$;

3. . 9.5 smoothing factor in eq (15);

4. The . 1 threshold in eqs (16) and (18);

5. .75 smoothing factor in eqs (17) and (19);

6. .55 limit in eq (20); and

7. .20 limit in eq (20) .

Two procedures are used for detection of a time jump change.

This change is signified by replacing $z_{t}$ with $z_{t}$ plus or minus a step as shown as follows:

$$
z_{t}=z_{t} \pm J
$$

The first procedure has 3 parameters and either detects or fails to detect jump $J$ on day $t$. Consider the filter

$$
p_{t}=.90 p_{t-1}+.10 z_{t-1}
$$

where $p_{1}=p_{2}=z_{1}$. We let $p_{t}$ predict the value $z_{t}$ and if

$$
\left|p_{t}-z_{t}\right|>3.4+.6 b
$$

we say that a jump must have been present at day $t$.

The second procedure using 5 parameters is a backup to the first since if

$$
\left|z_{t}\right|>2.8+.6 b
$$

and 


$$
\left|z_{t}\right|>4.8\left(\frac{\sum_{k=t-10}^{t-1} z_{k} \sum_{k=t+1}^{t+10} z_{k}}{20}\right)
$$

and

$$
\left|z_{k}\right|<.8\left|z_{t}\right| \text { for all } k=t-10, \ldots, t-1, t+1, \ldots, t+10
$$

we detect that a jump occurred at day t. A jump at day $t$ can only be detected at day $t$ or at day $t+10$ using these procedures.

The drift change conditions can be represented by letting

$$
z_{t}=z_{t} \pm D \pm Q\left(t-t_{c}\right)
$$

where ${ }_{c}$ is the day that the drift started.

A predictor

$$
r_{t}=.95 r_{t-1}+.05 z_{t}
$$

is compared to a 5-day moving average

$$
\bar{z}_{5}=\frac{\sum_{k=t-4}^{t} z_{k}}{5}
$$

in order to update one of four test quantities $P_{H^{\prime}}, P_{L}, N_{H^{\prime}}$ or $N_{L}$. The initial values at day $l$ are $P_{H}=N_{H}=.75$ and $P_{L}=N_{L}=.50$. The update is signified in replacement form as follows:

$$
\begin{aligned}
& \text { if } \mathrm{r}_{\mathrm{t}}>0 \text { and } \bar{z}_{5}>0 \text {, then } \mathrm{P}_{\mathrm{H}}=.8 \mathrm{P}_{\mathrm{H}}+.2 \bar{z}_{5} \\
& \text { or if } \mathrm{r}_{\mathrm{t}} \leq 0 \text { and } \bar{z}_{5} \leq 0 \text {, then } \mathrm{N}_{\mathrm{H}}=.8 \mathrm{~N}_{\mathrm{H}}-.2 \bar{z}_{5} \\
& \text { or if } \mathrm{r}_{\mathrm{t}}>0 \text { and } \bar{z}_{5} \leq 0 \text {, then } \mathrm{N}_{\mathrm{L}}=.8 \mathrm{~N}_{\mathrm{L}}-.2 \bar{z}_{5} \\
& \text { or if } \mathrm{r}_{\mathrm{t}} \leq 0 \text { and } \bar{z}_{5}>0 \text {, then } \mathrm{P}_{\mathrm{L}}=.8 \mathrm{P}_{\mathrm{L}}+.2 \bar{z}_{5} \text {. }
\end{aligned}
$$

The drift test is if

$$
\begin{aligned}
& \left(\mathrm{P}_{\mathrm{H}}-\mathrm{N}_{\mathrm{H}}>.5 \text { and } \mathrm{P}_{\mathrm{L}}>\mathrm{N}_{\mathrm{L}}\right) \\
& \text { or }\left(\mathrm{P}_{\mathrm{H}}-\mathrm{N}_{\mathrm{H}}>.7\right) \\
& \text { or }\left(\mathrm{P}_{\mathrm{L}}>.9 \mathrm{~N}_{\mathrm{H}} \text { and } \mathrm{P}_{\mathrm{H}}>.8\right)
\end{aligned}
$$


detect a drift in the positive direction, or if

$$
\begin{aligned}
& \left(\mathrm{P}_{\mathrm{H}}-\mathrm{N}_{\mathrm{H}}>.5 \text { and } \mathrm{P}_{\mathrm{L}}>\mathrm{N}_{\mathrm{L}}\right) \text { or }\left(\mathrm{P}_{\mathrm{H}}-\mathrm{N}_{\mathrm{H}}>.7\right) \\
& \text { or }\left(\mathrm{N}_{\mathrm{L}}>.9 \mathrm{P}_{\mathrm{H}} \text { and } \mathrm{N}_{\mathrm{H}}>.8\right)
\end{aligned}
$$

detect a drift in negative direction. This test using 9 parameters is made every 5 days.

\section{Experimental Development and Evaluation}

4.1. Development of the Detection Procedures

Considerable effort was required to verify and normalize the $\mathrm{Z}_{\mathrm{t}}$ generator so that $\sigma_{W}^{2}(1)$ and $\sigma_{F}^{2}(1)$ averaged out to 1 . The experimental evaluation of the noise model was by simulation. A sequence of $\mathrm{z}_{t}$ values was generated for $t=1,2, \ldots, 512$ days. At day $t_{c}$, usually around day 30, a change could be introduced of the type shown in eqs (13), (14), (21), or (27). If no change were made at day $t_{c}$ the run was said to be nominal.

The $\hat{\sigma}(\tau)$ estimator was studied. The parameter choices made were considered to be suitable. Longer averaging times have both advantages and disadvantages. A major drawback is that the estimator would require more than 16 days to start and would be less responsive to changes in the $\mathrm{a}$ and $\mathrm{b}$ variables. In the noise detection scheme the - 1 threshold parameter was chosen because it was near the outer edges of the variation experienced in $\hat{\sigma}(1)$ under nominal conditions. It is possible to detect noise changes of less than \pm .1 variation around either a or b.

In the case of the jump change the limit values in eqs (23) and (24) were chosen to balance falsely detecting a jump and actually detecting ones just inside the noise level. The .6b term in these limits reflects the apparently greater variation in the $\mathrm{F}_{t}$ process than in the $\mathrm{W}_{\mathrm{t}}$ process. 
The drift condition proved to be complex and the most difficult to detect. The motivation behind the $\mathrm{P}_{H}, \mathrm{~N}_{\mathrm{H}}, \mathrm{P}_{\mathrm{L}}$, and $\mathrm{N}_{\mathrm{L}}$ quantities (meaning positive high, negative high, positive low, and negative low, respectively) is as follows: The $z_{t}$ process is autocorrelated due to $\mathrm{bF}_{\mathrm{t}}$. The direction of the process is generally guided by the low frequency "energy" in the $\mathrm{bF}_{\mathrm{t}}$ process, while the higher frequencies generally come from the $a W_{t}$ process. The drifts $D$ or $Q$ of eq (27) can be in a positive or negative direction. (If the signs are different we must wait for $Q\left(t-t_{c}\right)$ to dominate.) Let us assume that the $r_{t}$ predictor in eq (28) indicates a positive direction and that a positive drift was introduced at day $t_{c} \cdot$ We contend that $\bar{z}_{5}$ will generally be greater in magnitude when it is in the same direction as $r_{t}$ and generally smaller in magnitude when it is running counter to $r_{t^{*}}$. The reason for this condition is that $\mathrm{D}$ and $\mathrm{Q}\left(\mathrm{t}-\mathrm{t}_{\mathrm{c}}\right)$ are additive in one case and subtractive in the counter case. Thus in this example explanation $P_{H}$ should be getting larger and $\mathrm{N}_{L}$ should be getting smaller. By reversing signs in the above example $\mathrm{N}_{\mathrm{H}}$ would get larger and $\mathrm{P}_{\mathrm{L}}$ smaller.

Several other schemes were tried using this same notion. They proved less effective until a very large number of days beyond day $t_{c}$. For D only not zero in eq (27) this scheme is complicated by the predictor gradually incorporating the $D$ term into the prediction of $\bar{z}_{5}$. It should also be noted that $D$ does not affect $\hat{\sigma}_{16}(\tau)$; the $Q$ term gradually will, however.

\subsection{Evaluation of the Detection Procedures}

We estimate that the time between false detections is on the average about 400 days when $\mathrm{b}=.3$. (The design center for these schemes was $\mathrm{a}=.7, \mathrm{~b}=.3$.) Recall that 1 year was desired overall. Very accurate estimates could not be made as many nominal runs went to 512 days without a false detection. Figures 1 to 5 display cumulative noise for 5 nominal runs that went to 512 days without detection. 
An evaluation of the jump change was made in 27 trials where $|\mathrm{J}|$ ranged from 3.0 to 4.6. We experienced 21 jumps detected and 6 jumps missed. Figures 6 to 9 display 4 of these 21 correctly detected jumps. Of the 6 trials where the jump was missed, 4 went to 512 days nominally (as they should have) while 1 drift and $1 \alpha<$ a condition were mistakenly detected. As $|J|$ increases, the chance of successfully detecting the jump also increases toward certainty.

In an evaluation of the time drift change consisting of 12 trials with $|\mathrm{D}|$ equal to 1.0 or 1.5 and $Q=0$, we obtained 9 correct detections, 2 missed detections which reported nominal to 512 days, and $1 \beta<\mathrm{b}$ mistake. The average number of days to make a $|D|=1.0$ detection was 83 while a $|D|=1.5$ detection was reduced to 27 days. Figures 10 and 11 show a correct $D=1.0$ and $D=1.5$ detection, respectively. A $|D|$ value around 3 might easily be mistaken for a jump. Values less than 1 require on the average more than 83 days to detect while values very near zero may not be detected much faster than the interval between false detections.

The rate drift change combined with a small time drift was evaluated in 10 trials; this resulted in 8 correct detections, 1 jump by mistake on the 6th day of drift and $1 \alpha<$ a condition on the 35 th day of drift. Had these 2 improper detections not been made so quickly, it is likely that all 10 rate drifts would have been properly detected. In the trials where $|D|=.1$ and $|Q|=.02$ the average number of days until detection was 76 while with $|D|=.2$ and $|Q|=.05$ the average was reduced to only 37 days. In practice, it is likely that $Q$ values would be near zero requiring a longer period of drift before proper detection is made. Figures 12 and 13 display correct detections of combined time and rate drifts. 
An evaluation of the noise change consisted of 45 trials where $\alpha=\mathrm{a} \pm .2$ and $\beta=\mathrm{b} \pm .2$. The overall results were that 19 correct detections were made; in addition we had 9 cases where the direction of the intensity was correctly sensed (a $\beta$ change was reported instead of an $\alpha$ or vice versa), while 17 mistakes or missed detections occurred. Of the 17 incorrect cases 11 were drifts, 4 were jumps, and 2 were nominal to 512 days. In the correct detection cases the average number of days observed to detect $\beta=\mathrm{b}+.2, \beta=\mathrm{b}-.2, \alpha=\mathrm{a}+.2, \alpha=\mathrm{a}-.2$ were about 200,175, 150, and 110 days, respectively. Figures 14 to 18 display 5 correct noise change detections.

The most successful detection by percentage was the $\alpha=a-.2$ followed by $\beta=\mathrm{b}-.2, \alpha=\mathrm{a}+.2$, with $\beta=\mathrm{b}+.2$ being the hardest change to detect. It appears that the reason for $\beta=b-.2$ being detected slowly (175 days) was the difficulty in distinguishing this change from the $\alpha=a-.2$ change rather than from nominal. Most of the mistaken drift detections occurred on the $\beta=b+.2$ and $\alpha=a+.2$ trials. It is easily seen why these mistakes occurred in trials where the $Z_{t}$ noise process has larger than nominal outcomes as opposed to the cases where $\mathrm{Z}_{\mathrm{t}}$ is lower than nominal. In the 9 cases where we detected the wrong reason for a noise intensity increase or decrease but the correct direction, it was because the likelihood of the change indicated was greater than the other non-nominal alternative. In the cases where $\alpha=\mathrm{a}-.2$ was detected instead of the proper $\beta=\mathrm{b}-.2$ condition, the detection interval averaged around 100 days. When more days were taken to make the detection, more chance of getting the proper reason was shown; logically, this represents an effectively larger sample size and thus should do better. Figures 19 to 23 display 5 noise changes that were not correctly detected by procedure in eq (20). 
An alternative way to check for a noise change might be to compute $\hat{\sigma}_{128}(\tau)$ for $\tau=1,2,4,8,16,32,64$, and perform an interpolation on $\hat{\sigma}_{128}(1)$ and $\hat{\sigma}_{128}(2)$. Then we could compute a likelihood of any change. However, in this method one may go a number of 128 day intervals before detecting a change since the $\hat{\sigma}_{128}(\tau)$ estimator experiences a fairly substantial amount of variation about the theoretical sigma $(a, b, \tau)$ values.

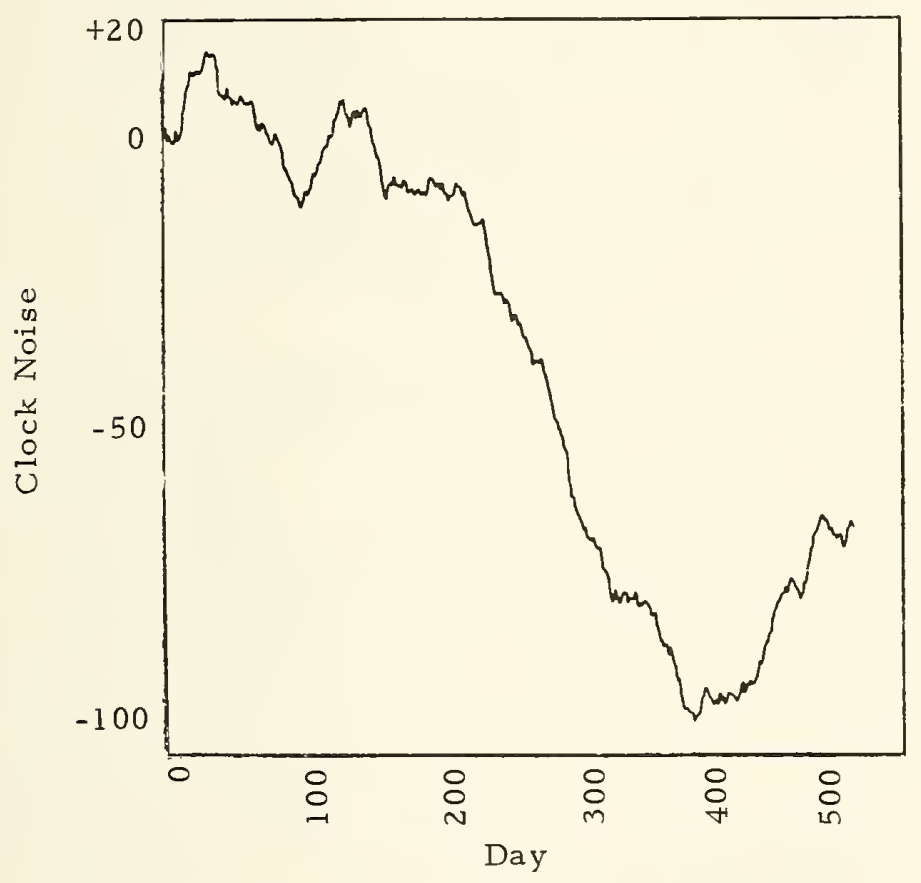

Figure 1. A nominal run with $(a, b)=(.7, .3)$ and no detection in 512 days. 


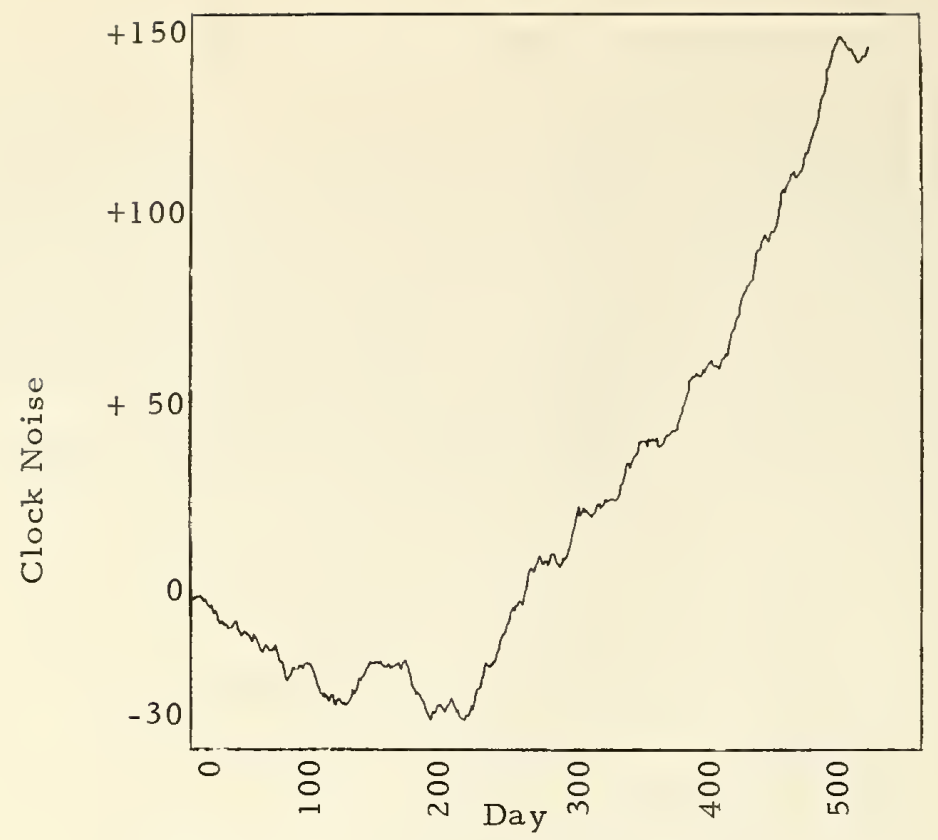

Figure 2. A nominal run with $(a, b)=(.7, .3)$ and no detection in 512 days.

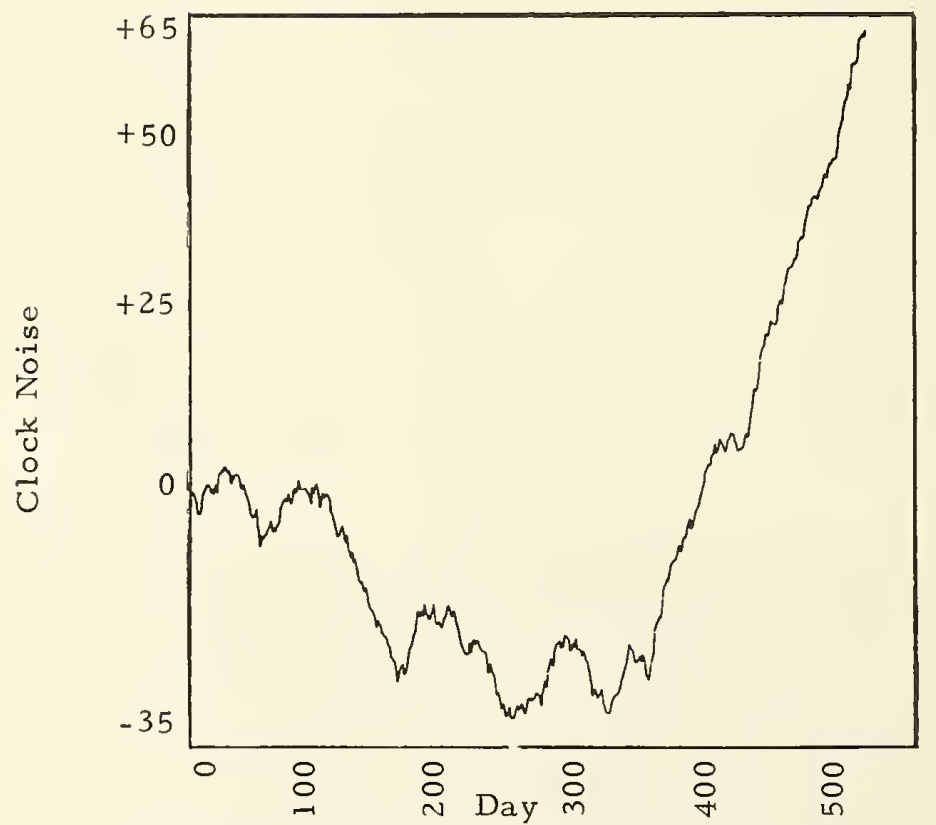

Figure 3. A nominal run with $(a, b)=(.8, .2)$ and no detection in 512 days. 


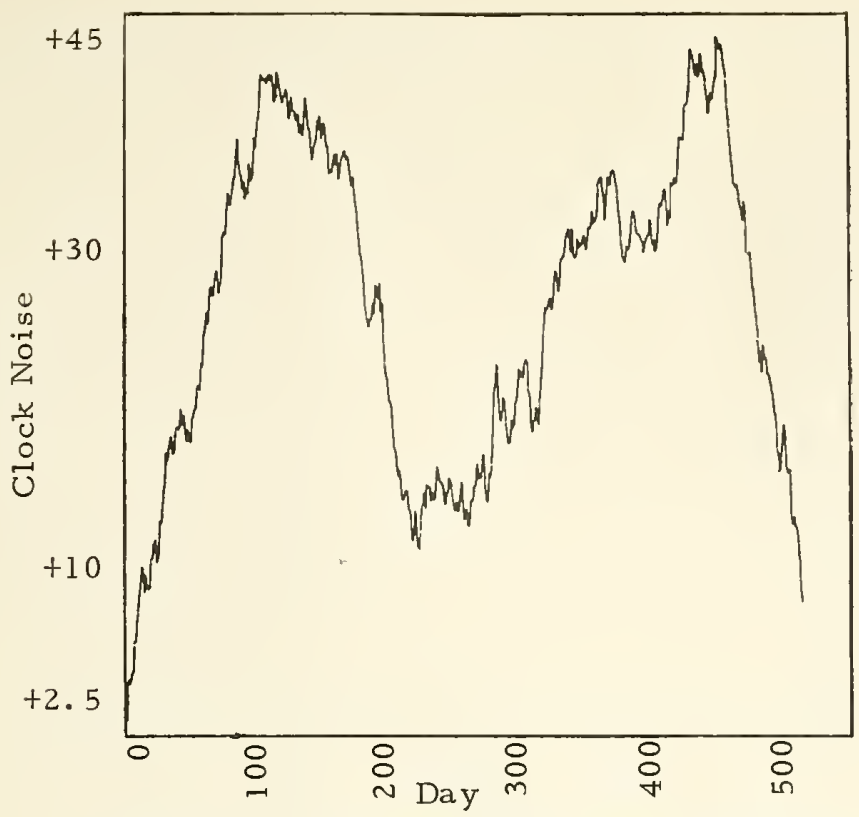

Figure 4. A nominal run with $(\mathrm{a}, \mathrm{b})=(.8, .2)$ and no detection in 512 days.

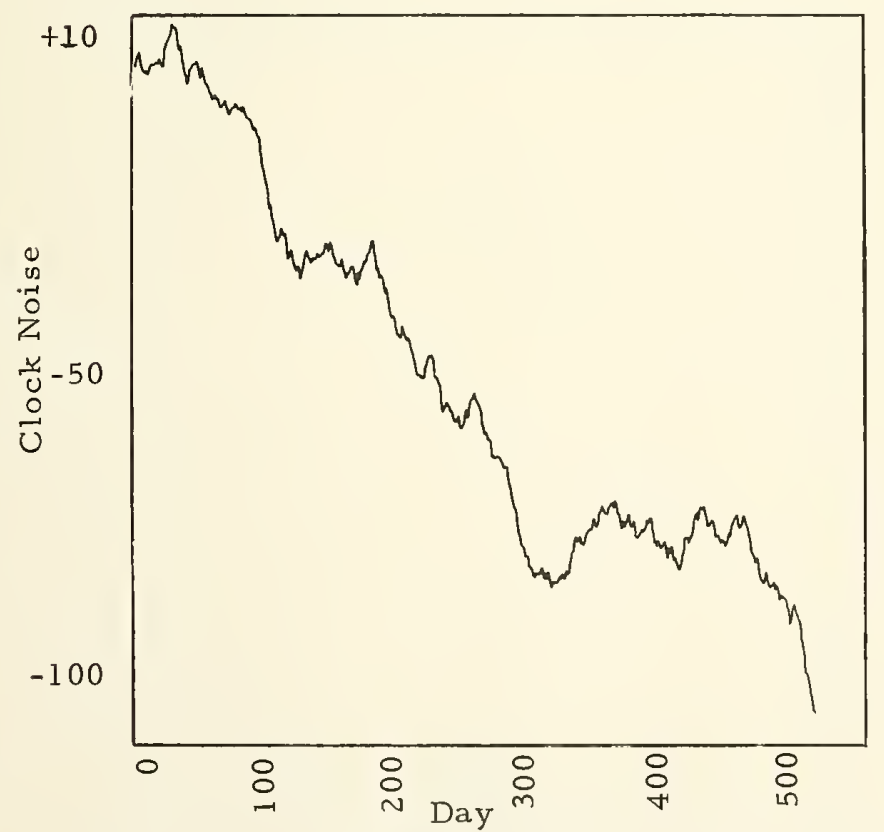

Figure 5. A nominal run with $(\mathrm{a}, \mathrm{b})=(.8, .2)$ and no detection in 512 days. 


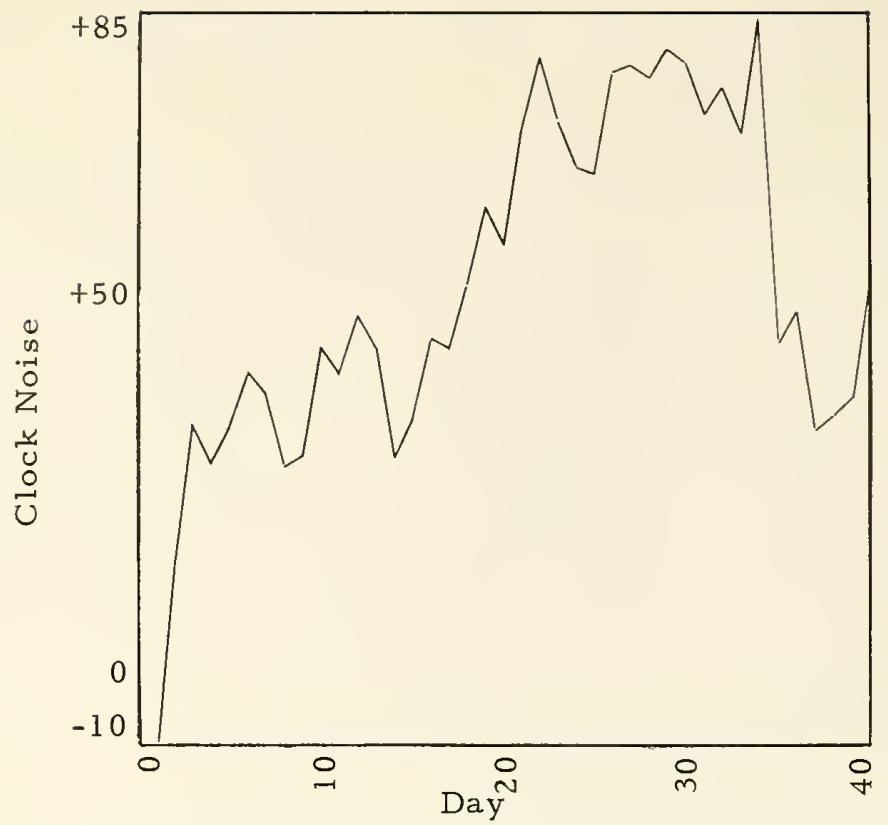

Figure 6. Detection of a $J=3.4$ jump by eq (23) when $(\mathrm{a}, \mathrm{b})=(.8, .2)$ and $\mathrm{t}_{\mathrm{c}}=35$.

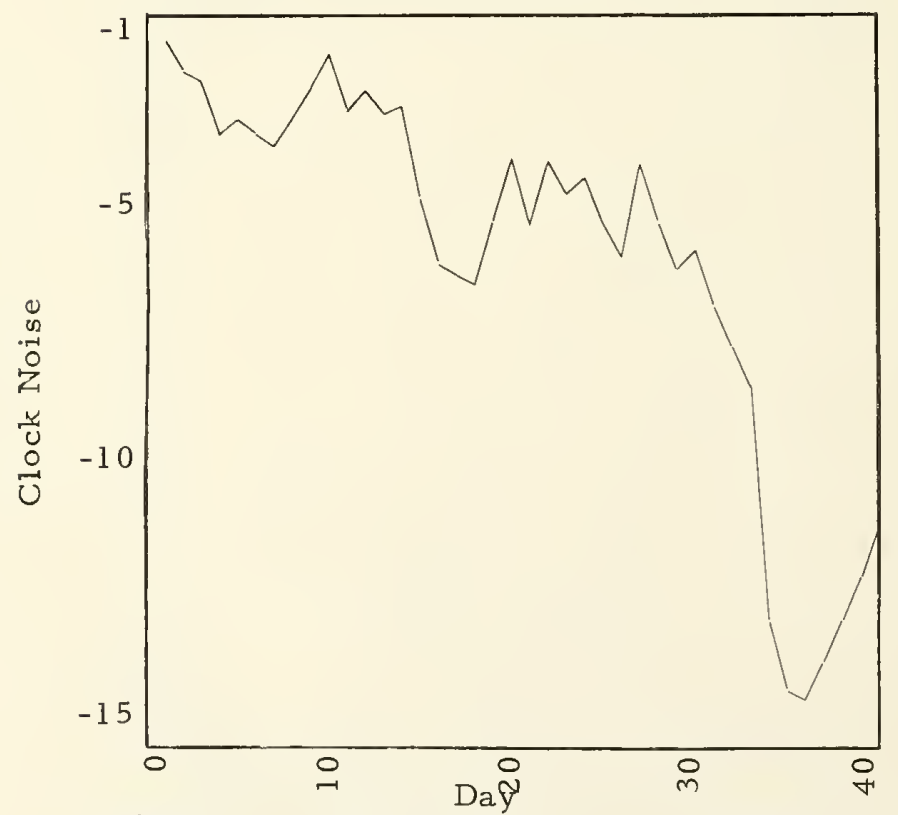

Figure 7. Detection of a $J=-3.2$ jump by eq (23) when $(a, b)=(.8, .2)$ and $t_{c}=34$. 


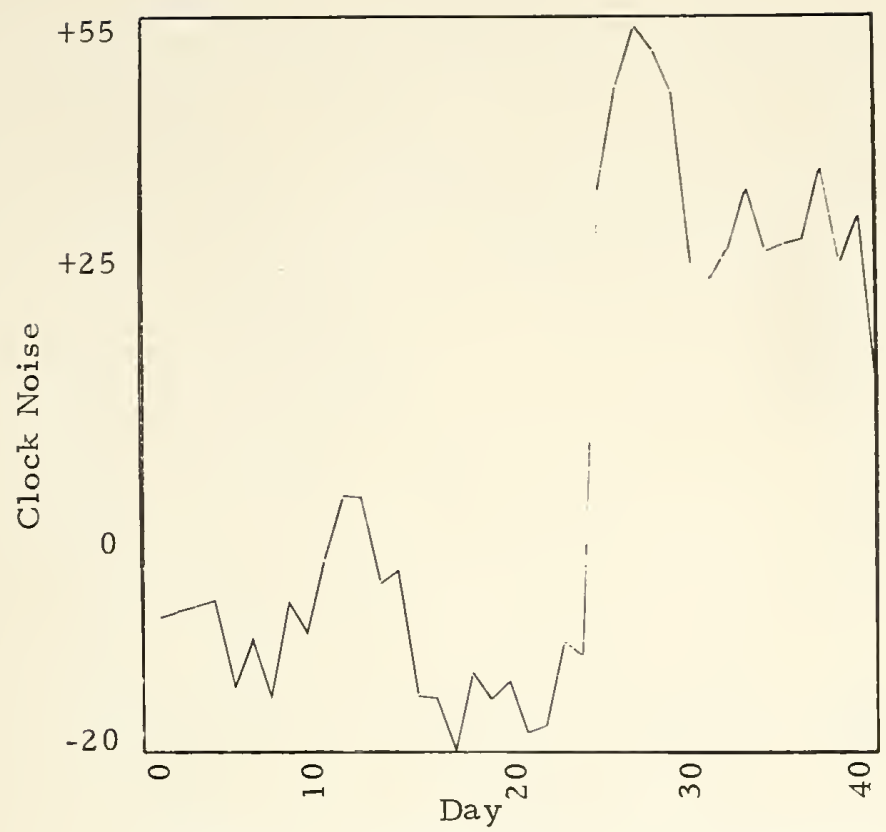

Figure 8. Detection of a $J=3.5$ jump by eq (23) when $(a, b)=(.7, .3)$ and $t_{c}=25$.

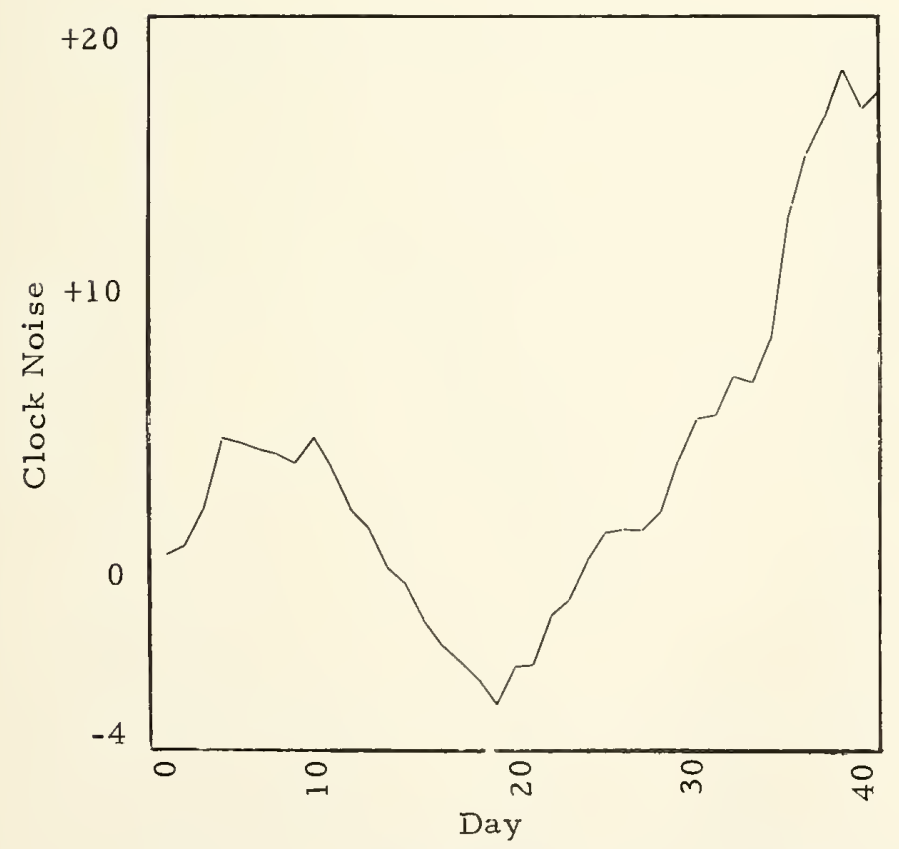

Figure 9. Detection of a $J=3.0$ jump by eqs (24-26) when $(a, b)-(.7, .3)$ and $t_{c}=35$. 


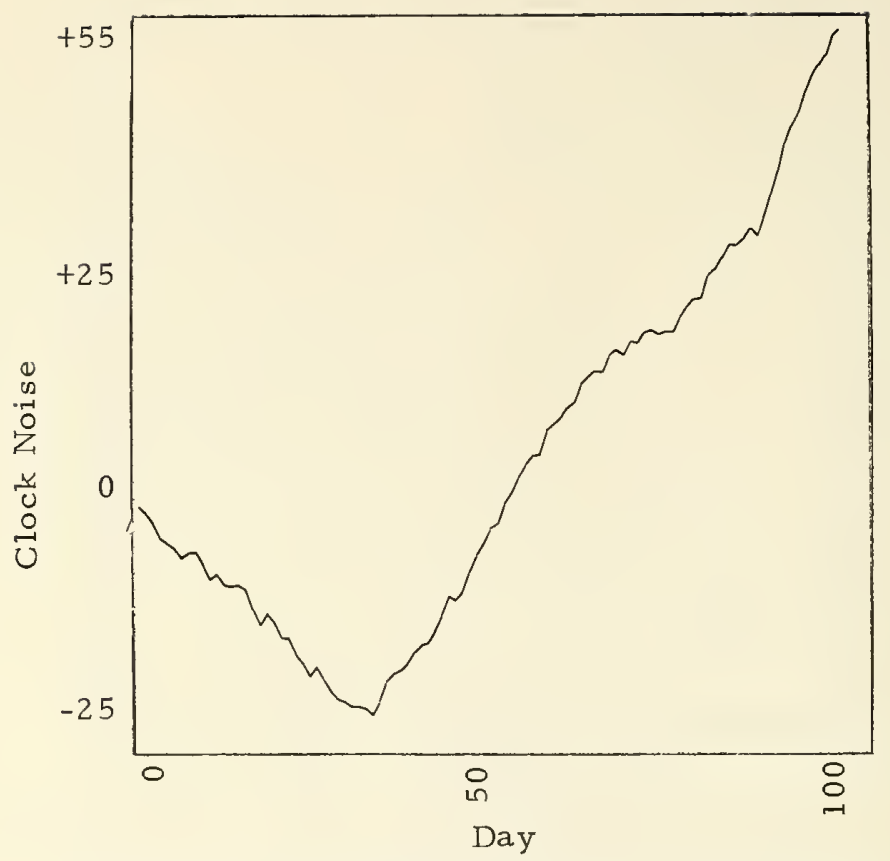

Figure 10. Detection of a $D=1.0$ time drift by eq (31) when $(a, b)=(.8, .2)$ and $t_{c}=35$.

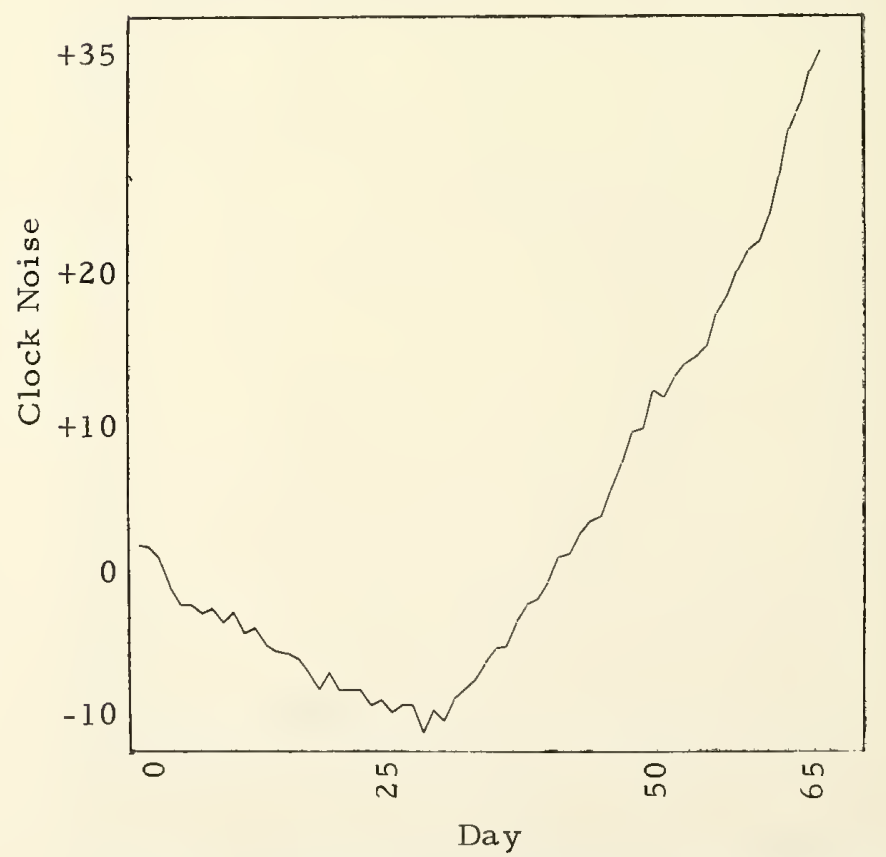

Figure 11. Detection of a $D=1.5$ time drift by eq (31) when $(a, b)-(.7, .3)$ and $t_{c}=31$. 


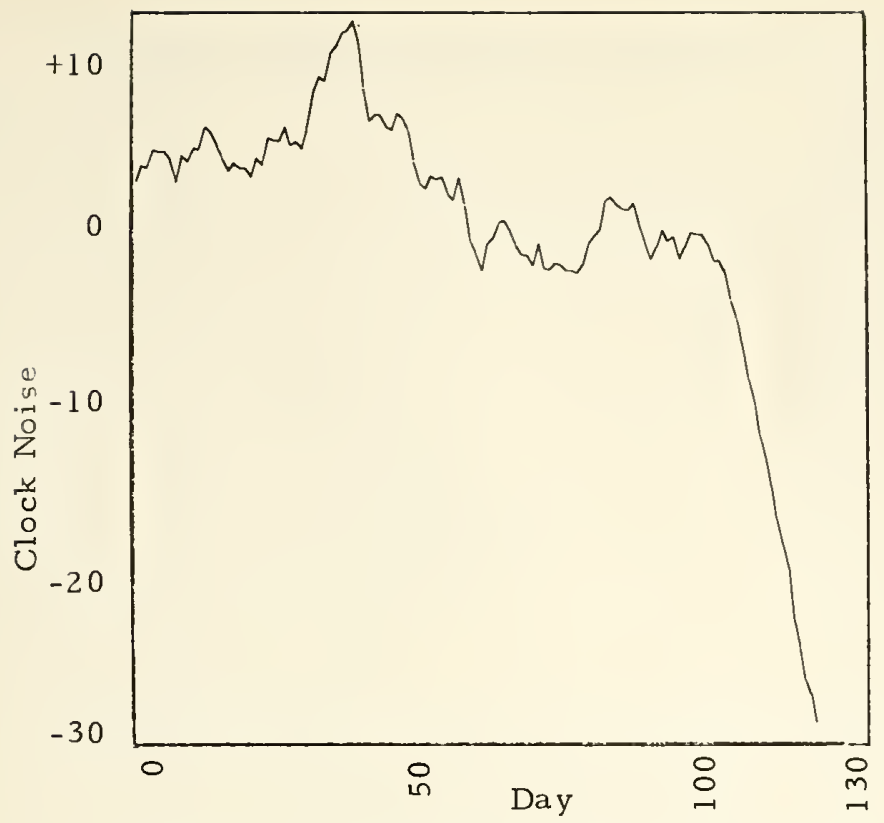

Figure 12. Detection of a $D=-.1, Q=-.02$ time and rate drift by eq (32) when $(a, b)-(.7, .3)$ and $t_{c}=28$.

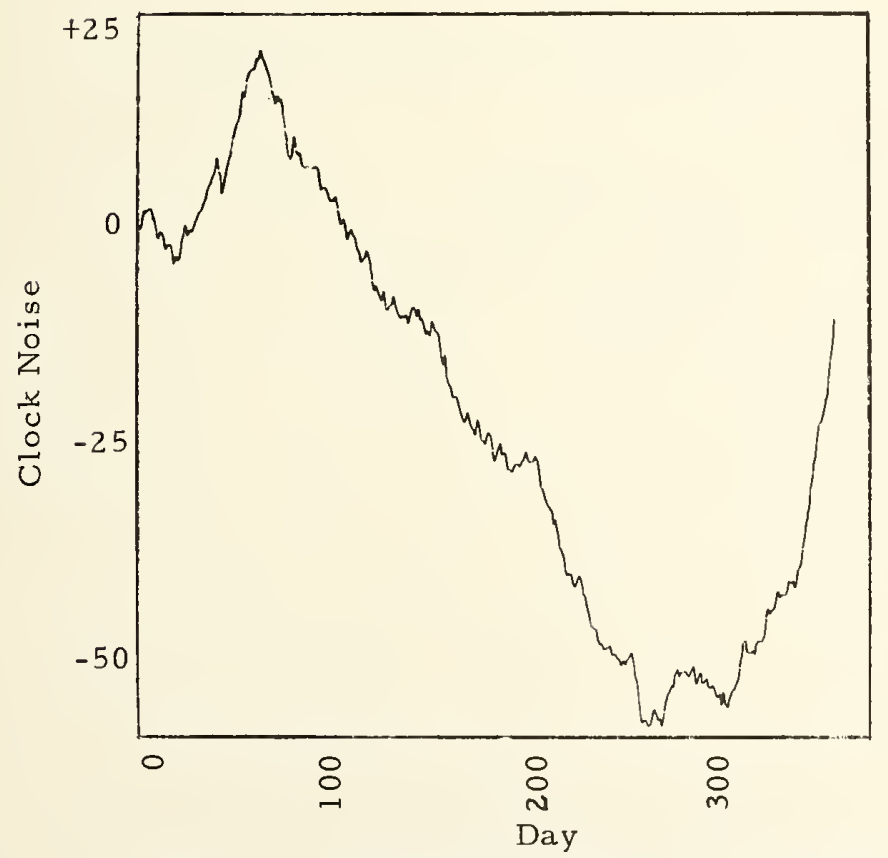

Figure 13. Detection of a $D=.2, Q=.05$ time and rate drift by eq $(31)$ when $(a, b)=(.7, .3)$ and $t_{c}=320$. 


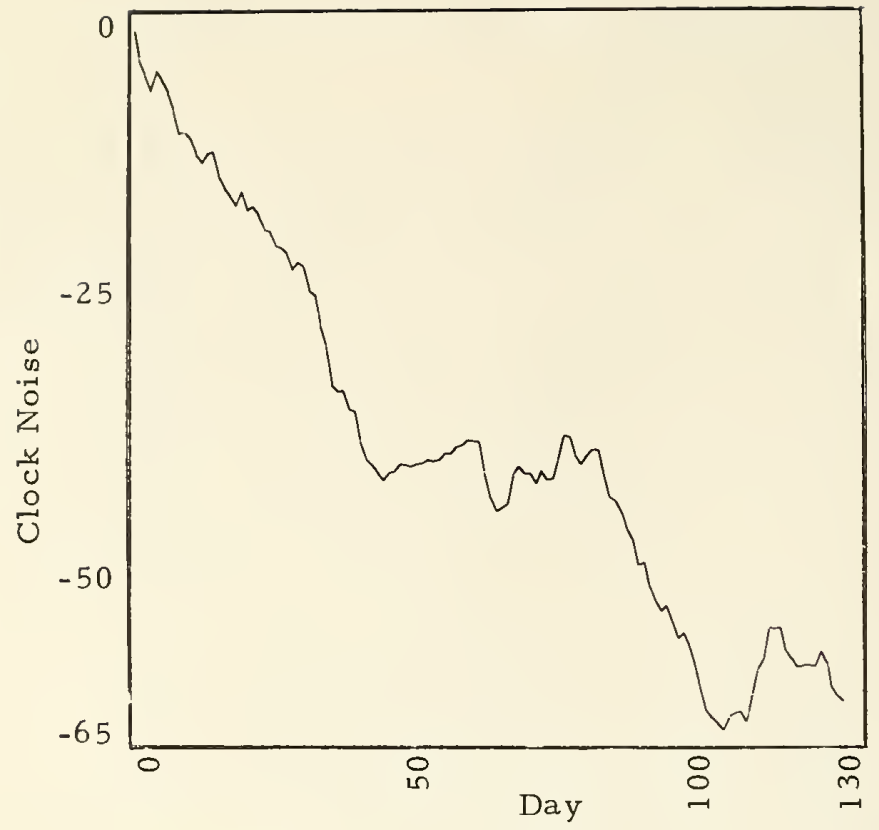

Figure 14. Detection at day 126 of noise change $\beta=.6$ when $(a, b)=(.7, .3)$ and $t_{c}=28$.

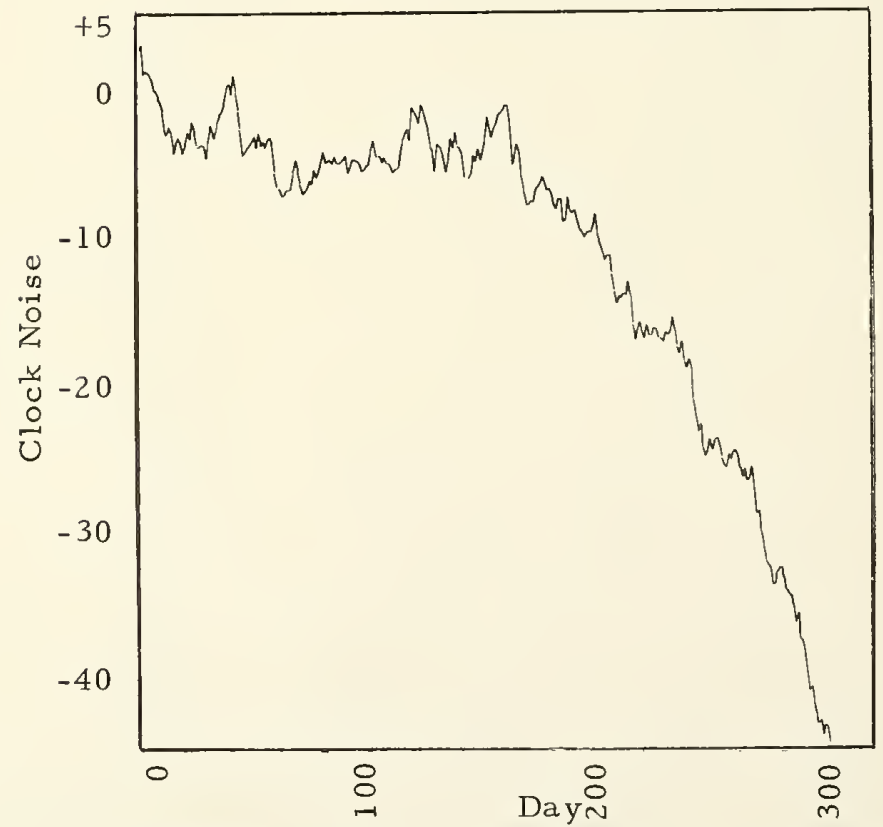

Figure 15. Detection at day 301 of noise change $\beta=.1$ when $(a, b)=(.7, .3)$ and $t_{c}=26$. 


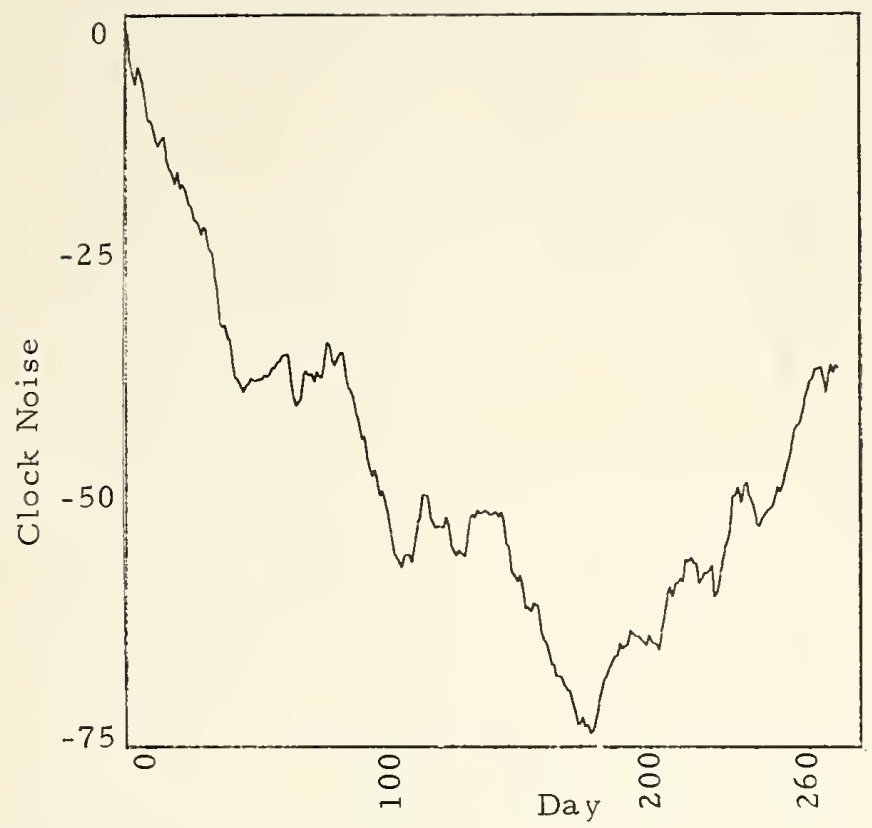

Figure 16. Detection at day 271 of noise change $\beta=.5$ when $(a, b)=(.7, .3)$ and $t_{c}=28$.

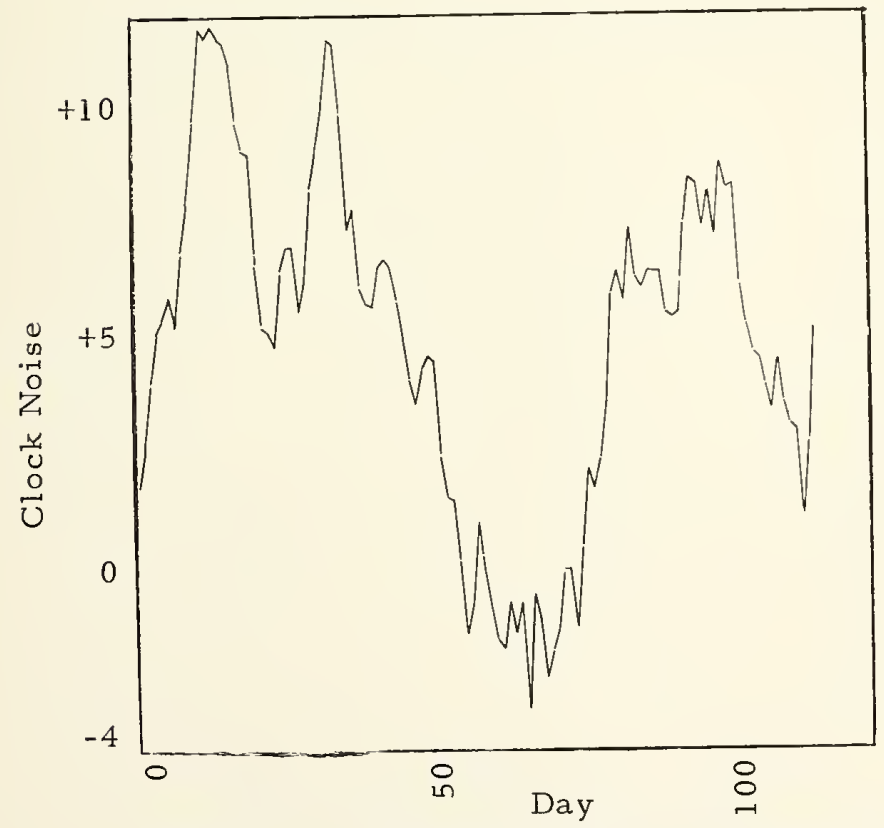

Figure 17. Detection at day 111 of noise change $\alpha=.9$ when $(a, b)=(.7, .3)$ and $t_{c}=24$. 


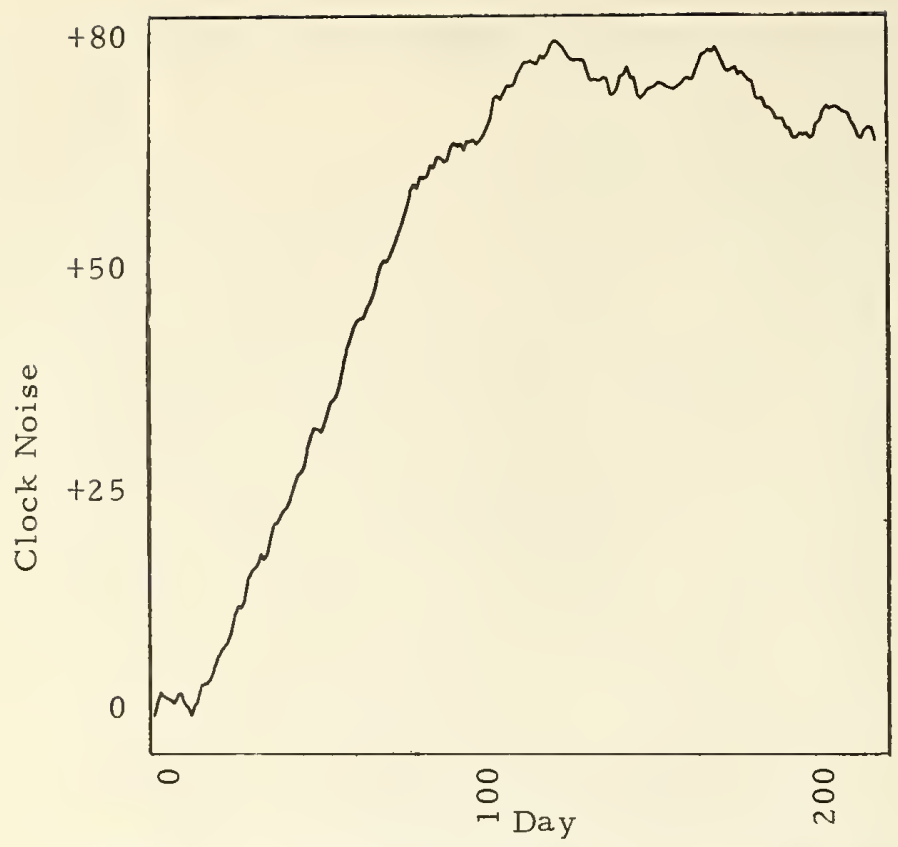

Figure 18. Detection at day 216 of noise change $\alpha=.5$ when $(a, b)=(.7, .3)$ and $t_{c}=28$.

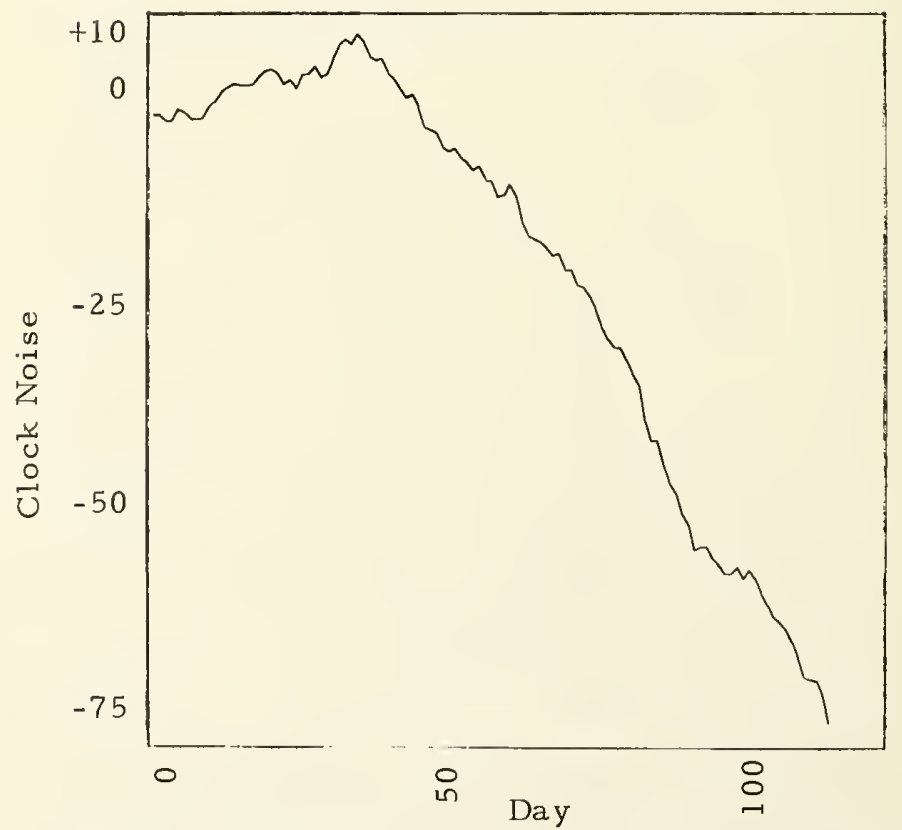

Figure 19. False inference at day 111 that $\alpha>.7$ when actually $\beta=.5 .(a, b)=(.7, .3)$ and $t_{c} 26$. 


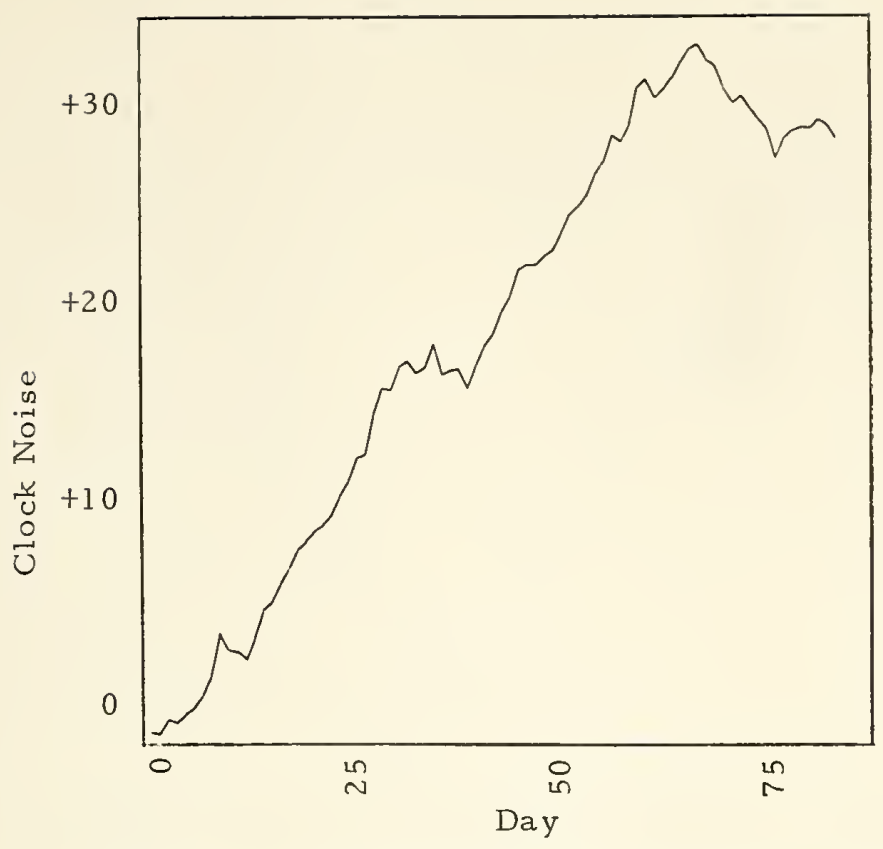

Figure 20. False inference at day 81 that $\alpha>.7$ when actually $\beta=.1 .(a, b)=(.7, .3)$ and $t_{c}=31$.

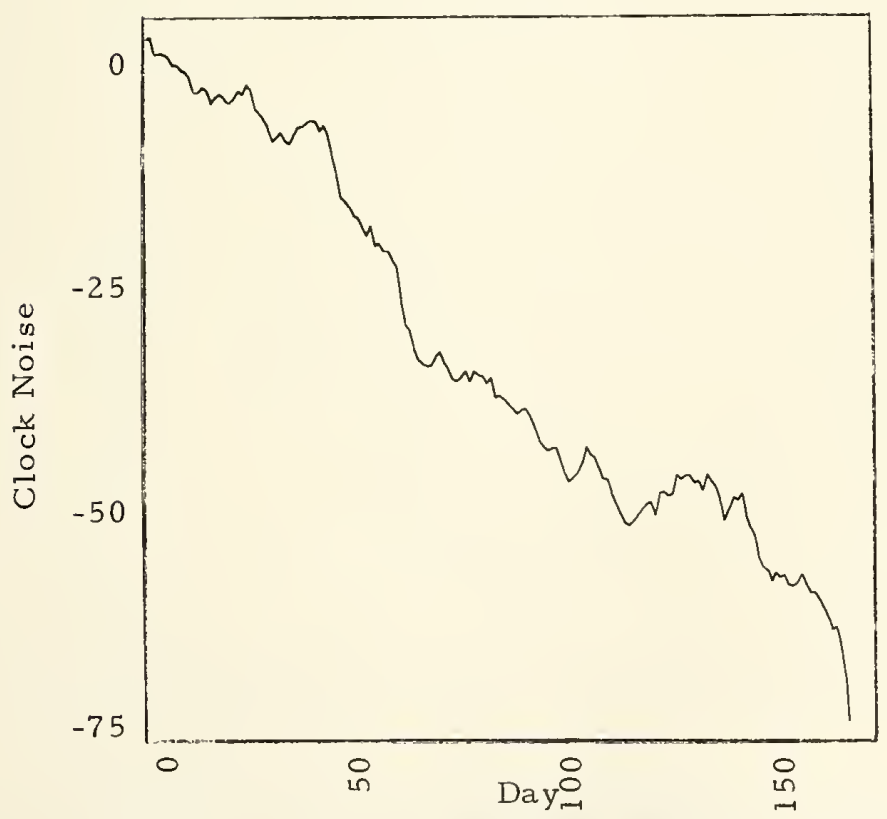

Figure 21. False detection of a jump by eq (23) at day 164 when actually $\beta=.5 .(a, b)=(.7, .3)$ and $t_{c}=28$. 


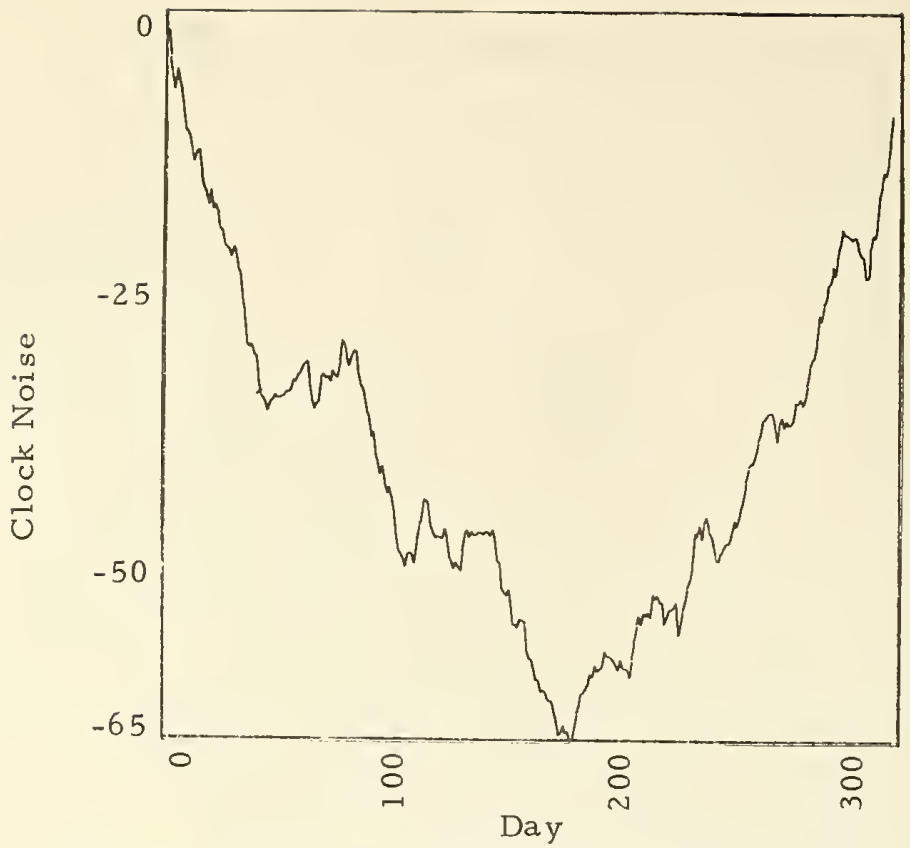

Figure 22. False detection of a drift by eq (31) at day 316 when actually $\beta=.4$. $(a, b)=(.7, .3)$ and $t_{c}=28$.

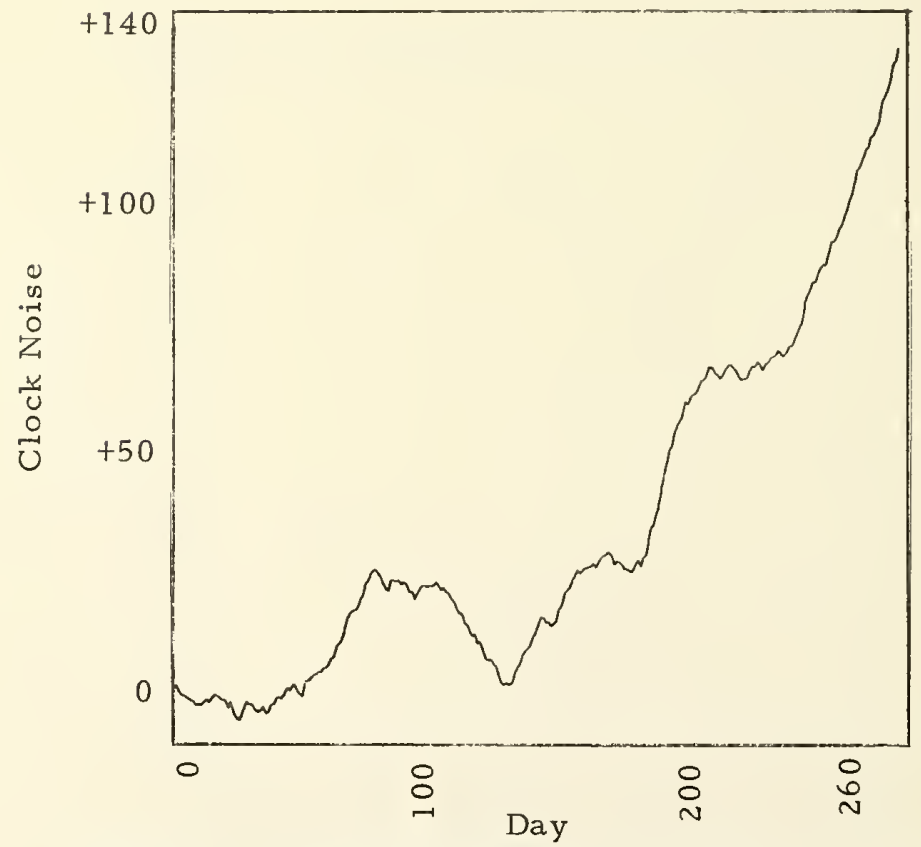

Figure 23. False detection of a drift by eq (31) at day 276 when actually $\beta=.4 .(a, b)=(.8, .2)$ and $t_{c}=29$. 


\section{Conclusions}

We can conclude that the false detection interval came out as desired. Also, nearly all of the runs where some change is introduced a detection is obtained; however, sometimes it is an incorrect detection. Rationale as to why mistakes are being made is available and enhances our insight into the difficulty of establishing the cause of any apparently non-nominal behavior of an individual clock in an ensemble. The experimental evaluation reported in section 4 was not intended to be comprehensive, but rather to give a general idea of successes and failures of these detection procedures.

The 24 parameters used is an unfortunately large number, however, the results indicate that even more sophisticated schemes might be necessary to obtain better discrimination; this could require even more parameters.

The problems of $\beta>\mathrm{b}$ in the noise process looking like drift and $\beta<\mathrm{b}$ appearing as though $\alpha<\mathrm{a}$ since $B$ cannot be allowed to go below zero when a lower than average $\hat{\sigma}(1)$ estimate is obtained can be resolved by specializing the test to the $b$ intensity to a greater degree. We can also be comforted by the contention that jumps within the noise level should not degrade a time scale very much.

It could be very useful to know more about the conditional distribution of $Z_{t+\tau}$ given knowledge of $Z_{k}$ for all $k \leq t$ as would other information about the $Z_{t}$ noise process in terms of classical mathematical statistics. It would also be useful to know more about the sampling distribution for $\hat{\sigma}_{T}(\tau)$. In short, there are many more things to be learned about detection of changes in atomic clock performance. However, it is hoped that some of the concepts discussed in this report will aid the ongoing effort of improving atomic time scales. 


\section{References}

[1] Allan, D. W., Gray, J. E., and Machlan, H. E., "The National Bureau of Standards atomic time scale system: Generation, dissemination, precision, and accuracy," IEEE Trans. Instrum. and Meas., IM-21, No. 4, pp. 388-391 (November 1972).

[2] Allan, D. W., "Statistics of atomic frequency standards," Proc. IEEE, 54, No. 2, pp. 221-230 (February 1966).

[3] Barnes, J. A., et al., "Characterization of frequency stability," IEEE Trans. Instrum. and Meas., IM-20, No. 2, pp. 105-120 (May 1971).

[4] Barnes, J. A., and Allan, D. W., "A statistical model of flicker noise," Proc. IEEE, 54, No. 2, pp. 199-207 (February 1966).

[5] Barnes, J. A., and Jarvis, Stephen, Jr., "Efficient numerical and analog modeling of flicker noise processes," NBS Technical Note 604 (June 1971). 


1. PUBLICATION OR REPORT NO.
NBS-TN-636

4. TITLE AND SUBTITLE

Modeling of Atomic Clock Performance and Detection of Abnormal Clock Behavior

2. Gov't Accession
No.

5.

5. Publication Date

March 1973

6. Performing Organization Code

8. Performing Organization

10. Project/Task/Work Unit No. 2730101

NATIONAL BUREAU OF STANDARDS, Boulder Labs. DEPARTMENT OF COMMERCE

Boulder, Colorado 80302
11. Contract/Grant No.

13. Type of Report \& Period Covered

Final

14. Sponsoring Agency Code

15. SUPPLEMENTARY NOTES

16. ABSTRACT ( $\mathrm{A} 200$-word or less factual summary of most significant information. If document includes a significant bibliography or literature survey, mention it here.)

We have assumed that the nominal performance of an atomic clock can be well characterized by (1) a noise amplitude and (2) a mix of white and flicker pure noise processes. A number of specific kinds of changes are assumed that a clock might encounter. We assume that these changes can occur with either sign and with varying magnitudes. The changes considered are a noise amplitude different from nominal, a flicker component in the noise mix which is different from nominal, a step jump in the time counts for a clock and a linear (frequency jump) or quadratic (frequency drift) trend in the time counts for a clock.

Detection of a change is accomplished with a multiple sequential test having compound limits. The test is designed to respond quickly to an actual change but to make few incorrect detections (identify the wrong change) or false detections (when no change from nominal operation has occurred). When a change is detected for a clock, the laboratory time scale can be adjusted accordingly for this condition.

17. KEY WORDS (AIphabetical order, separated by semicolons)

Atomic clock model; detection; flicker noise; sequential test; time scale.

\section{AVAILABILITY STATEMENT}

$\mathrm{X}$ UNLIMITED.

FOR OFFICIAL DISTRIBUTION. DO NOT RELEASE TO NTIS.

\begin{tabular}{|c|c|}
$\begin{array}{c}\text { 19. SECURITY CLASS } \\
\text { (THIS REPORT) }\end{array}$ & 21. NO. OF PAGES \\
UNCL ASSIFIED & 39 \\
\hline $\begin{array}{l}\text { (THIS PAGE) } \\
\text { SECUR ITY CLASS }\end{array}$ & 22. Price \\
UNCL ASSIFIED & 50 \\
\hline
\end{tabular}





\section{NBS TECHNICAL PUBLICATIONS}

PERIODICALS

JOURNAL OF RESEARCH reports National Burcau of Standards research and development in phrsics, mathematics, and chemistry. Comprehensive scientific papers give complete details of the work. including laboratory data, experimental proccdures, and theorctical and mathematical analyses. Illustrated with photographs, drawings, and charts. Includes listings of other NBS papers as issued.

Published in two sections, azailable separately:

\section{- Physics and Chemistry (Section A)}

Papers of interest primarily to scientists working in these fields. This section covers a broad range of physical and chemical research, with major emphasis on standards of physical measurement, fundamental constants, and properties of matter. Issued six times a year. Annual subscription: Domestic, $\$ 17.00$; Foreign, $\$ 21.25$.

\section{- Mathematical Sciences (Section B)}

Studies and compilations designed mainly for the mathematician and theoretical physicist. Topics in mathematical statistics, theory of experiment design, numcrical analysis, theoretical physics and chemistry, logical design and programming of computers and computcr systems. Short numerical tables. Issued quarterly. Annual subscription: Domestic, $\$ 9.00$; Foreign, $\$ 11.25$.

\section{TECHNICAL NEWS BULLETIN}

The best single source of information concerning the Bureau's measurement, research, developinental, coopcrative, and publication activities, this monthly publication is designed for the industry-oriented individual whose daily work involves intimate contact with science and technology-for engineers, chemists, physicists, research managers, product-development managers, and company executives. Includes listing of all NBS papers as issued. Annual subscription: Domestic, \$6.50; Foreign, $\$ 8.25$.
NONPERIODICALS

Applied Mathematics Series. Mathematical tables, manuals, and studies.

Building Science Series. Research results, test methods, and performance criteria of building materials, components, systems, and structures.

Handbooks. Rccommended codes of engineering and industrial practice (including safety codes) developed in cooperation with interested industries, professional organizations, and regulatory bodies.

Special Publications. Proceedings of NBS conferences, bibliographies, annual reports, wall charts, pamphlets, etc.

Monographs. Major contributions to the technical literature on various subjects related to the Bureau's scientific and technical activities.

National Standard Reference Data Series. NSRDS provides quantitative data on the physical and chemical properties of materials, compiled from the world's literature and critically evaluated.

Product Standards. Provide requirements for sizes, types, quality, and methods for testing various industrial products. These standards are developed cooperativcly with interested Government and industry groups and provide the basis for common understanding of product characteristics for both buyers and sellers. Their use is voluntary.

Technical Notes. This series consists of communications and reports covering both other-agency and NBS-sponsored work) of limited or transitory interest.

Federal Information Processing Standards Publications. This series is the official publication within the Federal Government for information on standards adopted and promulgated under the Public Law 89-306, and Bureau of the Budget Circular A-86 entitled, Standardization of Data Elements and Codes in Data Systems.

Consumer Information Series. Practical information. based on NBS research and experience, covering areas of interest to the consumer. Easily understandable language and illustrations provide useful background knowledge for shopping in today's technological marketplace.

\section{BIBLIOGRAPHIC SUBSCRIPTION SERVICES}

The following current-awareness and literature-survey bibliographies are issued periodically by the Bureau :

"yyogenic Data Center Current Awareness Service (Publications and Reports of Interest in Cryogenics). A literature survey issued weekly. Annual subscription: Domestic, $\$ 20.00$; foreign, $\$ 25.00$.

Liquefied Natural Gas. A literature survey issued quarterly. Annual subscription: $\$ 20.00$.

Superconducting Devices and Materials. A literature survey issued quarterly. Annual subscription: \$20.00. Send subscription orders and remittances for the preceding bibliographic services to the U.S. Department of Commerce, National Technical Information Service, Springfield, Va. 22151.

Electromagnetic Metrology Current Awareness Service (Abstracts of Selected Articles on Measurement Techniques and Standards of Electromagnetic Quantities from D-C to Millimeter-Wave Frequencies). Issued monthly. Annual subscription: $\$ 100.00$ (Special rates for multi-subscriptions). Send subscription order and remittance to the Electromagnetic Metrology Information Center, Electromagnetics Division, National Bureau of Standards, Boulder, Colo. 80302.

Order NBS publications (exccpt Bibliographic Subscription Services) from: Supcrintendent of Documcnts, Government Printing Office, Washington, D.C. 20402. 
U.S. DEPARTMENT OF COMMERCE

National Bureau of Standards

Washington, D.C. 20234

PDSTAGE AND FEES PAID

OFFICIAL BUSINESS

U.S. DEPARTMENT OF COMMERCE

215

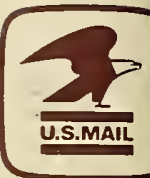

Penalty for Private Use. \$3D0 